University of Nebraska - Lincoln

DigitalCommons@University of Nebraska - Lincoln

Agronomy \& Horticulture -- Faculty Publications

Agronomy and Horticulture Department

1969

Environmental Manipulation for Higher Yields

Paul Waggoner

Connecticut Agricultural Experiment Station, New Haven, Connecticut

Follow this and additional works at: https://digitalcommons.unl.edu/agronomyfacpub

Part of the Plant Sciences Commons

Waggoner, Paul, "Environmental Manipulation for Higher Yields" (1969). Agronomy \& Horticulture -Faculty Publications. 193.

https://digitalcommons.unl.edu/agronomyfacpub/193

This Article is brought to you for free and open access by the Agronomy and Horticulture Department at DigitalCommons@University of Nebraska - Lincoln. It has been accepted for inclusion in Agronomy \& Horticulture -Faculty Publications by an authorized administrator of DigitalCommons@University of Nebraska - Lincoln. 
Published in Physiological Aspects of Crop Yield: Proceedings of a symposium sponsored by the University of Nebraska, the American Society of Agronomy, and the Crop Science Society of America, and held at the University of Nebraska, Lincoln, Nebr., January 20-24, 1969. Edited by Jerry D. Eastin, F. A. Haskins, C. Y. Sullivan, C. H. M. Van Bavel, and Richard C. Dinauer (Madison, Wisconsin: American Society of Agronomy \& Crop Science Society of America, 1969). Copyright (C) 1969 American Society of Agronomy \& Crop Science Society of America. Used by permission. 


\title{
15
}

\section{Environmental Manipulation for Higher Yields}

\author{
PAUL E. WAGGONER \\ Connecticut Agricultural Experiment Station \\ New Haven, Connecticuf
}

\section{INTRODUCTION}

My role in this chapter on environmental manipulations is making a prediction that can be used until experiments render the final verdict.

In chapters preceding mine, an array of physical and physiological phenomena for affecting yield has been laid before the grower of plants. Predicting whether environmental manipulation will increase yield requires that all of these phenomena be considered for foreign lands are littered with the bleaching bones of immigrant varieties and practices that were ambushed by an unsuspected environmental difference.

Interaction is the Scylla of biologic prediction. Formerly we predicted by drawing a curve or writing a formula relating yield to some factor. We used this although common sense told us that the rock of some limiting factor would surely sink us. We simply couldn't accommodate all the factors that common sense told us would be important. For example, we knew light and $\mathrm{CO}_{3}$ would alter the relation between ventilation and yield, but considering them was beyond our capacity.

Now, however, high-speed and capacious information machines give more latitude to our common sense by permitting us to include things that formerly had to be discarded in simplification. The empirical curve is easily replaced by a simulator that not only produces a prediction but also, in its interior, works like the crop. The degree to which it works like the crop is always imperfect, but passages toward realism are now easily found, and more reefs of interaction missed. Light and $\mathrm{CO}_{2}$, for example, can now be considered in predicting the the effect of ventilation upon yield.

The simulator required for predicting yield response to environmental manipulation must combine meteorology and physiology. The reason is easily seen in the example of $\mathrm{CO}_{2}$. It is delivered via a meteorological thing, turbulence, and the receipt is through a physiological thing, the stomata, into a photochemical process.

Models of leaves have been drawn by electrical analogy: a current 
of $\mathrm{CO}_{2}$ is driven by the difference in $\mathrm{CO}_{2}$ concentration between the air about a single leaf and its interior, and the current is opposed by boundary layer, stomatal and mesophyll resistors (Gaastra, 1959; Moss, 1966; El-Sharkawy, Loomis and Williams, 1967; Lake, 1967; and Bravdo, 1968). A current of respired $\mathrm{CO}_{z}$ enters the conductor, too. The model has been refined (Waggoner, 1969) by separating the mesophyll resistor into physical and biochemical parts, by separating the respiration into light and dark portions, and by making the resistors functions of light, $\mathrm{CO}_{2}$ and temperature. Clearly this leaf model or simulator needs connection to a meteorological simulator.

The microclimate simulator that I shall use incorporates the radiation and ventilation profiles within the canopy, the leaf area and stomatal resistance, and the conditions above and below the canopy. It calculates the temperature, humidity, and evaporation within the canopy and the resistances and leaf temperatures that affect $\mathrm{CO}_{2}$ exchange (Waggoner and Reifsnyder, 1968; Waggoner et al., 1969).

In this chapter, a simulator of the photosynthesis in a canopy is made by setting the physiological simulator of a single leaf in the framework of the microclimate simulator. The resulting photosynthesis simulator then accepts the news of environmental manipulation and predicts the changes in photosynthesis and, hopefully, yield.

In the following pages, I shall first present the entire simulator. Then its reasonableness will be tested by calculating temperature, photosynthesis and $\mathrm{CO}_{2}$ profiles from normal characteristics of weather, stand geometry and physiology and comparing the profiles to actual observations. Then the effect of stomatal aperture, light, ventilation and $\mathrm{CO}_{2}$ management will be predicted.

\section{THE PHOTOSYNTHESIS SIMULATOR}

Since our goal is a photosynthesis simulator, a mathematical guinea pig, with parts that function much like the real thing, the simulator is presented from the inside parts out. That is, considerably physiology of a single leaf is incorporated into the model of a single leaf and then this is, in turn, incorporated into a meteorological framework for the entire canopy.

An electrical conductor is shown in Fig. 15-1A. This is an analog of the leaf. The potential at one end of the conductor is, in fact, $C$, the $\mathrm{CO}_{2}$ concentration at the outer edge of the boundary layer around a single leaf. At the other end of the conductor, the $\mathrm{CO}_{2}$ concentration is zero where $\mathrm{CO}_{2}$ becomes carbohydrate. Since the system is nonisothermal, relative concentrations, as ppm, are used.

The unit of net assimilation $\mathrm{P}$ of $\mathrm{CO}_{2}$ that has become predominant is $\mathrm{mg} \mathrm{CO} \mathrm{Cm}_{2}^{-2} \mathrm{hr}^{-1}$. In the case of the single leaf the $\mathrm{dm}^{2}$ refers to the projected area of a flat leaf, which is $2 \mathrm{dm}^{2}$ of leaf surface. In the following pages, this long and awkward unit is abbreviated by " $F$ ". The direction of the current is shown as inward, which it will be in the normal, illuminated leaf. On the other hand, the current will of ten be outward as when the leaf is not illuminated or the outside air is devoid of 
A.

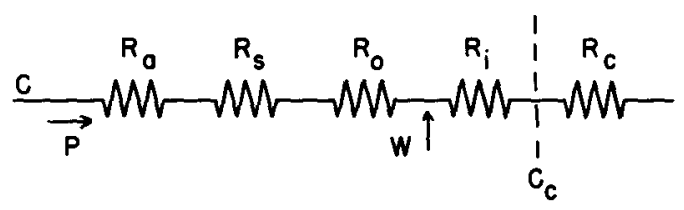

B.

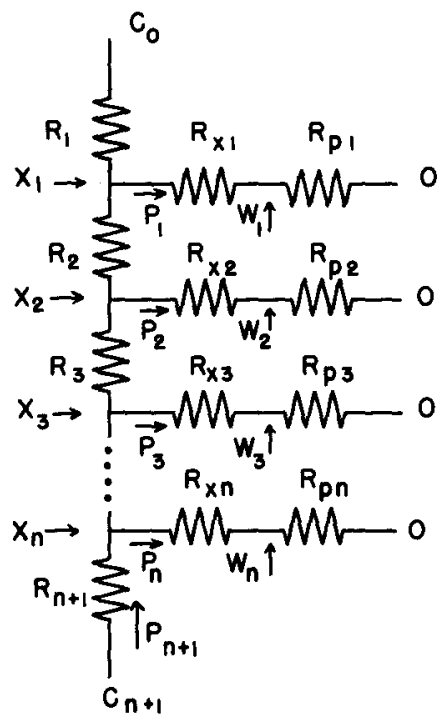

Fig. 15-1-Simulators drawn as electrical circuits for (A) a single leaf and (B) a canopy of leaves.

$\mathrm{CO}_{2}$; no change in convention is required in this case for the current will simply appear as negative in the calculations.

The resistances have dimensions $\sec \mathrm{cm}^{-1}$. The net assimilation current $P$ passes first through the resistance $R_{a}$ of the boundary layer outside the epidermis of the leaf. In the epidermis, the current encounters $R_{S}$, the diffusive resistance of the stomata. Inside the leaf, the current encounters another diffusive resistance, $R_{0}$. Formally, this resistance is between the stomata and the junction where the net assimilation current $\mathrm{P}$ is joined by the current $\mathrm{W}$ of $\mathrm{CO}_{2}$ that comes from respiration within the leaf. Physically, $R_{0}$ must be in the substomatal cavity, the cell walls and the outer cell contents. Inside the outer resistance, $R_{O}$, may be an inner one, $R_{i}$. This $R_{i}$ separates the junction of $\mathrm{P}$ and $\mathrm{W}$ from the biochemical site where the concentration of $\mathrm{CO}_{3}$ has fallen to $\mathrm{C}_{c}$. Chemical factors that lie between $\mathrm{C}_{c}$ and the final reduction to zero concentration are represented by a final resistance $R_{c}$. The resistance $R_{a}$ is calculated in the microclimate simulator, and $R_{i}$ and $R_{0}$ are assumed independent of environment. The other parameters of Fig. 15-1A vary with environment as is now specified. 
The current $\mathrm{W}$ of $\mathrm{CO}_{2}$ is composed of $\mathrm{W}_{\mathrm{d}}$ that proceeds in the dark or light and $W_{1}$ that occurs only in the light. The Wd has a well-known $Q_{10}$ or temperature response of about 2 ; that is, $W_{d}$ doubles when the temperature increases from 20 to 30C (Altman and Dittmer, 1966). On the other hand, $\mathrm{W}_{\mathrm{d}}$ seems unaffected by light (Marsh, Galmiche, and Gibbs, 1965) and is assumed unaffected by $\mathrm{CO}_{2}$. If the $Q_{10}$ for dark respiration is called Qwd, then Wd at temperature $T$ can be calculated by an Arrhenius equation with $W_{d x}$ as the rate at $20 \mathrm{C}$.

$$
\mathrm{W}_{\mathrm{d}}=\mathrm{W}_{\mathrm{dx}} \exp \left[9000 \ln \left(\mathrm{Qwd}_{\mathrm{w}}\right)(1 / 293-1 / \mathrm{T})\right]
$$

Wdx can reasonably be assigned a value of $2 \mathrm{~F}$ (Altman and Dittmer, 1966). Since the Arrhenius equation will be used again, it is abbreviated "arh," and equation (1) can be written

$$
\mathrm{W}_{\mathrm{d}}=\operatorname{arh}\left(\mathrm{W}_{\mathrm{dx}}, \mathrm{Qwd}_{\mathrm{wd}} \mathrm{T}\right) \text {. }
$$

The portion $W_{1}$ of the current $W$ that proceeds in the light also increases with temperature. The burst of $\mathrm{CO}_{2}$ following darkening, an indication of $\mathrm{W}_{1}$, has a $\mathrm{Q}_{\mathrm{wl}}$ of 1.4 to 3.4 (Decker, 1959). The burst was unaffected by $\mathrm{CO}_{2}$, but its response to light can be represented by a MichaelisMenten equation, which represents the observations in a form familiar to chemists. Thus at $20 \mathrm{C}$

$$
\mathrm{w}_{1}=\frac{\mathrm{w}_{1 x^{L}}}{\left(\mathrm{~K}_{\mathrm{wl}}+\mathrm{L}\right)}
$$

$W_{l x}$ is the maximum $W_{l}$ at $20 \mathrm{C}$, and $\mathrm{K}_{\mathrm{Wl}}$ is the irradiance $\mathrm{L}$ that causes half $W_{1 x}$ to be realized. Decker's (1959) observations indicate $K_{w l}$ is about $1 \mathrm{cal} \mathrm{cm}^{-2} \mathrm{~min}^{-1}\left(1 \mathrm{y} \mathrm{min} \mathrm{m}^{-1}\right)$. The parameters concerning irradiance are stated in values for insolation, i.e., the energy between 400 and $3,000 \mathrm{~nm}$.

The $\mathrm{CO}_{2}$ current $W \mathrm{Wx}$ is close to zero in maize (Zea mays) but might exceed net assimilation in tobacco (Nicotiana tabacum) at 35 C (Zelitch, 1966). Jackson and Volk (1968) have reported that maize leaves take up more oxygen in the light than in the dark. Since the maize leaves do not, however, release $\mathrm{CO}_{2}$ into $\mathrm{CO}_{3}$-free air during photosynthesis, the existence of an $\mathrm{O}_{2}$ current does not require an increase in the $\mathrm{CO}_{2}$ current $W$ in Fig. 15-1 when maize is illuminated. Thus $W l x$ of 0 and 10 $\mathrm{mg} \mathrm{dm} \mathrm{dr}^{-2} \mathrm{hr}^{-1}$ are not unreasonable for an efficient and for a mediocre species, respectively. Respiration in the light can now be expressed as a realistic function of temperature and irradiance:

$$
W_{1}=\operatorname{arh}\left(W_{1 x}, Q_{w l} T\right) \times \frac{L}{\left(K_{w l}+L\right)}
$$

Estimating $R_{c}$ presents special problems. It represents the obstacle to gross photosynthesis in a photosynthetic site (unencumbered by other resistances) per unit of $\mathrm{C}_{c}$, the $\mathrm{CO}_{2}$ concentration at the boundary of the site. If the effects of temperature, light and $\mathrm{CO}_{2}$ upon that 
photosynthesis were independent of one another, it would be reasonable to employ the familiar Michaelis-Menten and Arrhenius equations and set gross photosynthesis equal to

$$
\operatorname{arh}\left(P_{x}, Q_{p}, T\right) \frac{L}{K_{c l}+L} \frac{C_{c}}{K_{c c}+C_{c}} .
$$

Then the resistance to gross photosynthesis per unit of $\mathrm{C}_{c}$ is

$$
\mathrm{R}_{\mathrm{c}}=\frac{\left(\mathrm{K}_{\mathrm{cl}}+\mathrm{L}\right)}{\mathrm{L}}\left(\mathrm{K}_{\mathrm{cc}}+\mathrm{C}_{\mathrm{c}}\right) / \operatorname{arh}\left(\mathrm{P}_{\mathrm{x}}, \mathrm{Q}_{\mathrm{p}}, \mathrm{T}\right) .
$$

The reader will understand that the units of concentrations of $\mathrm{CO}_{2}$ and of $P_{X}$ must be converted to obtain $R_{C}$ in sec $\mathrm{cm}^{-1}$.

Since no naked photosynthetic sites without respiration are available for observation, the parameters of equation (4) were estimated from observations of maize, which has small resistance and respiration. The $Q_{p}$ is 2 to 3 (Moss, 1965). The maximum photosynthesis at $20 \mathrm{C}, \mathrm{P}_{\mathrm{X}}$, is about $120 \mathrm{~F} ; \mathrm{K}_{\mathrm{cl}}, 0.5 \mathrm{ly} \mathrm{min}^{-1}$ and $\mathrm{K}_{\mathrm{cc}}, 300 \mathrm{ppm}$ (Hesketh, 1963; Hesketh and Moss, 1963).

$\mathrm{R}_{\mathrm{S}}$ varies with both illumination and $\mathrm{CO}_{2}$. Since the effect of $\mathrm{CO}_{2}$ is much less than illumination (Gaastra, 1959), calculating $\mathbf{R}_{\mathbf{S}}$ as follows is reasonable:

$$
R_{s}=R_{s m} \frac{K_{s l}+L}{L}
$$

$R_{\mathrm{Sm}}$ is the minimum stomatal resistance, which is attained in bright light, and $K_{S l}$ is the insolation that makes $R_{S}$ twice $R_{S m}$.

As stated in the Introduction, the goal is to incorporate as much physiology and as much common sense as possible into the model, making it run something like a real leaf. Equations (1) through (5) have taken us in that direction. Boundary layer, stomatal resistance, light and dark respiration, diffusive resistance in the leaf interior, and the response of the photosynthetic apparatus itself can all be identified explicitly in the equations or model. To facilitate the connection of Fig. $15-1 \mathrm{~A}$ to the simulator of the canopy, some symbols are combined. The sum of the resistors external to $W$ is called $R_{X}$, and the sum of those inside $W$ is called $R_{p}$. Thus, Fig. 15-A becomes simpler and is seen in Fig. 15-1B where it represents the leaf strata of a canopy.

A canopy of leaves is conceived as a ladder of conductors, Fig. 15$1 \mathrm{~B}$, between a $\mathrm{CO}_{2}$ concentration $\mathrm{C}_{\mathrm{O}}$ at the top of the plants and a concentration $\mathrm{C}_{n+1}$ near the soil. The canopy is divided into $\mathrm{n}$ strata. Later, when the simulator has been assembled and calculations are possible, I shall demonstrate that the stratified canopy is practically equal to the continuous one in the real field or forest.

By integrating the reciprocal of the diffusivity from the upper to lower boundary of each stratum, the resistance $R$ is obtained. This is the diffusive resistance offered to $\mathrm{CO}_{2}$ as it moves through the bulk air 
in a stratum and is the same resistance employed for water vapor or sensible heat (Waggoner and Reifsnyder, 1968). On its way down the ladder, $\mathrm{CO}_{2}$ may pass on to another rung or stratum, or it may move into the leaves of a stratum, encountering $R_{X}$ and, after joining $W$, passing through $R_{p}$ to a sink and concentration zero.

At this point, the effect of leaf area upon $R_{X}, W$, and $R_{p}$ must be mentioned. In Fig. 15-1A, a unit area of leaf surface was tacitly assumed. That is, the $R_{a}$ and $R_{S}$ pertain to a $\mathrm{cm}^{2}$ of epidermis, while the other resistors and the $W$ pertain to the $\mathrm{cm}^{2}$ of mesophyll enclosed between $2 \mathrm{~cm}^{2}$ of epidermis (i.e., $2 \mathrm{~cm}^{2}$ of total surface of a flat leaf). In the full canopy, however, the $R_{X}, R_{p}$, and $W$ pertain to the variable areas encountered at the different levels. Thus, $R_{a}$ and $R_{S}$, which pertain to epidermis, are divided by twice the projected leaf area index in each stratum. The other resistors pertain to the leaf interior and are divided by leaf area index in each stratum. Respiration is multiplied by leaf area index in each stratum. In this way, the parameters for $1 \mathrm{~cm}^{2}$ of leaf in Fig. 15-1A are adapted to the variable areas in the strata of the canopy in Fig. 15-1B and now pertain to $1 \mathrm{~cm}^{2}$ of land.

At the bottom of the canopy, another sink or source is encountered. The diffusive resistance among the bare stems is $R_{n+1}$. If these stems are long and ventilation penetrates poorly to this recess, $R_{n+1}$ will be great. At its bottom, the end of the conductor is reached, and the $\mathrm{CO}_{2}$ concentration near the soil is specified. If it is $\mathrm{CO}_{2}-\mathrm{rich}$, an upward current $\mathrm{P}_{\mathrm{n}+1}$ will move into the canopy.

If we are to simulate $\mathrm{CO}_{2}$ fertilization, external sources $\mathrm{X}$ of $\mathrm{CO}_{2}$ mustalso be considered. These are shown as $\mathrm{X}_{1}, \mathrm{X}_{2}, \ldots ., \mathrm{X}_{\mathrm{n}}$ entering the strata of Fig. 15-1B. Like the respiratory currents $W$, the advected currents $\mathrm{X}$ are considered independent of $\mathrm{CO}_{3}$ concentration. Physically, the $X$ could be the respiration of an ear of grain, gas from a flue, or evaporating dry ice measured in a stratum as $\mathrm{mg} \mathrm{CO}_{2}$ per $\mathrm{dm}^{2}$ of land per hour or $\mathbf{F}$.

The model of the canopy and its leaves have now been presented in words and graphs and must be reduced to equations that can be solved for the $P_{1}, P_{2}, \ldots, P_{n+1}$. The equations will also provide values for $\mathrm{C}_{1}, \mathrm{C}_{2}, \ldots ., \mathrm{C}_{\mathrm{n}}$, which are the $\mathrm{CO}_{2}$ concentrations at the junction of $R_{1}$ and $R_{X 1}, R_{3}$ and $R_{X} 2, \ldots, R_{n}$ and $R_{x n}$. These are assumed to be the concentrations that a micrometeorologist would measure within the canopy.

The equations are simply obtained from the assumed equality between concentration differences and the products of currents and resistances. Thus, between the air at the top and the interior of the leaves in the first stratum,

$$
C_{0}-0=P_{0} R_{1}+P_{1} R_{x l}+\left(P_{1}+W_{1}\right) R_{p l}
$$

where

$$
P_{0}=P_{1}+P_{2}+\ldots P_{n}-P_{n-1}-\left(X_{1}+X_{2}+\ldots+X_{n}\right)
$$

Between the interiors of the leaves in the first and second strata 


$$
\begin{aligned}
0-0= & -\left(P_{1}+W_{1}\right) R_{p 1}-P_{1} R_{x 1} \\
& +\left(P_{0}-P_{1}+X_{1}\right) R_{2}+P_{2} R_{x 2}+\left(P_{2}+W_{2}\right) R_{p 2}
\end{aligned}
$$

Finally, at the bottom,

$$
\begin{aligned}
0-C_{n+1}= & -\left(P_{n}+W_{n}\right) R_{p n}-P_{n} R_{x n} \\
& -P_{n+1} R_{n+1} .
\end{aligned}
$$

Equation (6) from the canopy top, the n-1 equations like (8) from the canopy interior, and equation (9) from the canopy bottom can be written in matrix form:

$$
[\mathrm{A}][\mathrm{P}]+[\mathrm{B}]-[\mathrm{D}][\mathrm{X}]=[\mathrm{C}] \text {. }
$$

The elements $A_{k j}$ of the $(n+1) x(n+1)$ matrix [A] are

$$
\begin{array}{cl}
0 & j<k-1 \\
-R_{x, k-1}-R_{p, k-1} & j=k-1 \\
R_{k}+R_{x k}+R_{p k} & j=k \text { and } k<n-1 \\
R_{x} & j=k=n+1 \text { or } j>k .
\end{array}
$$

The elements of the column vector $[\mathrm{P}]$ are $\mathrm{P}_{1}, \mathrm{P}_{2}, \ldots, \mathrm{P}_{\mathrm{n}+\mathbf{1}}$.

The elements of the column vector [B] pertain to respiration and are $W_{1} R_{p 1},\left(-W_{1} R_{p 1}+W_{2} R_{p 2}\right), \ldots,\left(-W_{n-1} R_{p, n-1}+W_{n} R_{p n}\right),-W_{n} R_{p n}$

The elements of $D_{k j}$ of the $(n+1) x(n+1)$ matrix [D] are

$$
\begin{array}{ll}
0 & \mathrm{j}<\mathrm{k} \\
\mathrm{R}_{\mathrm{k}} & \mathrm{j} \geq \mathrm{k} .
\end{array}
$$

For the column vector $[\mathrm{X}]$, the elements are the external $\mathrm{CO}_{2}$ sources $\mathrm{X}_{1}, \mathrm{X}_{2}, \ldots \mathrm{X}_{\mathrm{n}}, 0$. Finally, the elements of the column vector [C] are $\mathrm{C}_{0}, 0, \ldots, 0,-\mathrm{C}_{\mathrm{n}+1}$.

Equation (10) is easily solved for net assimilation in each stratum:

$$
[\mathrm{P}]=[\mathrm{A}]^{-1}[\mathrm{C}]-[\mathrm{A}]^{-1}[\mathrm{~B}]+[\mathrm{A}]^{-1}[\mathrm{D}][\mathrm{X}]
$$


These values of net assimilation cannot be accepted, however, until their effect upon the concentration $\mathrm{C}_{\mathrm{c}}$ at the photosynthetic site and hence upon $R_{c}$ and $R_{p}$ have been considered. $C_{c}$ for each stratum is calculated as the product of $(P+W)$ times $R_{C}$. This statement does not, of course, require that all of $\mathrm{W}$ go inward: If $\mathrm{P}$ is negative, $\mathrm{P}+\mathrm{W}$ will be less than $\mathrm{W}$, and $\mathrm{CO}_{2}$ will escape from the leaf. This $\mathrm{C}_{c}$ then permits a revised $R_{C}$ to be calculated by means of equation (4) for each stratum. Then the calculation of $P_{1}, P_{2}, \ldots, P_{n+1}$ by equation (11) is repeated. This repeated refinement of the net assimilation values is repeated until the refinement in all strata is less than or equal to $1 \%$ or, in the case of small values, less than or equal to $0.1 \mathrm{~F}$. In five calculations with 14 to $23 \mathrm{~F}$ net assimilation in the entire canopy, equation (11) was applied four times in each example. The fourth and last refinement changed the canopy sum .06 to $.3 \mathrm{~F}$.

With values of $\mathrm{P}_{1}, \mathrm{P}_{2}, \ldots, \mathrm{P}_{\mathrm{n}}$ at hand, the $\mathrm{CO}_{2}$ concentrations $\mathrm{C}_{1}$, $\mathrm{C}_{2}, \ldots, \mathrm{C}_{\mathrm{n}}$ within the canopy can be calculated. For example,

$$
\mathrm{C}_{3}=\left(\mathrm{R}_{\mathrm{x} 3}+\mathrm{R}_{\mathrm{p} 3}\right) \mathrm{P}_{3}+\mathrm{R}_{\mathrm{p} 3} \mathrm{~W}_{3} \text {. }
$$

This completes the specification of the model by parameters that are identified meteorological or physiologic factors.

At the conclusion of this derivation of the photosynthesis simulator, the differences between it and models designed to consider only the manipulation of light (e.g., Loomis et al., 1968) is clear. The present simulator considers several physiological factors that were not incorporated into the light models. Equally important, it considers ventilation, temperature and $\mathrm{CO}_{2}$ in the environment. In its meteorological nature, the present simulator is more closely related to the proposals of Inoue (1965) than to the light models.

Now it is time to test the microclimate and photosynthetic simulators operating in tandem. If they are logical and the published information about the parameters is adequate, the simulation should be realistic both in function and in calculated values.

\section{THE RUNNING OF THE SIMULATORS}

Within a few minutes of 1400 hours on September 11, 1963, Lemon (1967) and his colleagues observed the wind, temperature, humidity and $\mathrm{CO}_{3}$ concentration within a maize crop in New York State and then calculated the photosynthesis. Simultaneous observations made nearby by L.H. Allen, K.W. Brown, and J.L. Wright have generously been furnished to me.

If the microclimate and photosynthesis simulators described above are valid, I should be able to put into them the physiological characters of maize, e.g., lack of light respiration and low stomatal resistance, together with the ventilation, radiation and plant size observed by Lemon, and then synthesize the humidity, temperature and $\mathrm{CO}_{2}$ profiles that he observed. I should also obtain the same rate of photosynthesis that he did if our methods are compatible. 
When I set out the known factors, however, two are missing: stomatal resistance and leaf temperature. In 1963 we were not aware of the great importance of stomata and had no handy porometer available. In the case of temperature, the objective was to measure transport in the air, and hence, air-not leaf-temperature was reported. The microclimate simulator comes to the rescue, however. I can enter in it the observations that are available and various stomatal resistances and then select the stomatal resistance that causes the microclimate simulator to mimic the temperature and humidity profiles within the canopy. Leaf temperatures will automatically be calculated by the microclimate simulator.

The next paragraph is necessary because it concerns my choices and adjustments among Lemon's data. But it is tedious, and the reader who is uninterested in detail can skip a paragraph.

The highest leaf was evidently about $225 \mathrm{~cm}$ above the ground, and I have assumed that the lowest $25 \mathrm{~cm}$ of stem was leafless. K.W. Brown measured the leaf area as follows: 250 to $200 \mathrm{~cm}$ above the ground, $0.20 \mathrm{~cm}^{2} \mathrm{~cm}^{-2}, 200$ to $150,1.27 ; 1.50$ to $100,1.30 ; 100$ to $50,1.00 ; 50$ to $0,0.55$. I have assigned the area to nine $25-\mathrm{cm}$-thick strata from bottom to top: $0.20,0.65,0.62,0.65,0.65,0.50,0.50,0.55,0$. Lemon (1967) gave the distribution of $300-700 \mathrm{~nm}$ radiation in his Fig. 20 . The absorption of this radiation in each stratum divided by the leaf area provides an estimate of the equivalent irradiance perpendicular to the leaf. K.W. Brown observed the net, all-wave radiation as follows: 250 $\mathrm{cm}$ above the ground, $0.639 \mathrm{ly} \mathrm{min}^{-1} ; 200,0.643 ; 150,0.411 ; 100,0.160$; $50,0.150$. I have assigned the absorption to the nine strata from top to bottom: $0.5 \mathrm{ly} \mathrm{min}^{-1}$ per stratum, 1.7, 1.6, 1.4, 1.2, 0.9, 0.8, 0.7, 0 . The wind at canopy top was $246 \mathrm{~cm} \mathrm{sec}^{-1}$, and Lemon (1967) shows its average extinction within the canopy during the day was 3 . This coefficient pertains to an exponential equation and relative height with in the canopy (Uchijima, 1962). To calculate the boundary layer resistance, I assumed that the leaf dimension was $1 \mathrm{~cm}$ and that the wind was extinguished exponentially with height and a coefficient of 3 . The specification of the diffusivity presents a greater problem. When Lemon (1967) calculated itfrom the wind and leaf area profiles, he found that diffusivity decreased very little with height in the upper and then very greatly in the lower canopy. Since the wind profile is opposite-i.e., it decreases greatly in the upper and little in the lower canopy-and since wind speed is observed directly, I have accepted Lemon's estimate of diffusivity at canopy top $\left(1,140 \mathrm{~cm}^{2} \mathrm{sec}^{-1}\right)$ but have extinguished it within the canopy in the pattern Lemon observed in the wind. Thus, the resistances of the bulk air within the strata were calculated from the following diffusivities: $1,140 \mathrm{~cm}^{2} \mathrm{sec}^{-1}, 810,480,380,290,280,260,260$, 260. This concludes the specification of the canopy, its ventilation and its absorption of radiation. Now the effects of different stomatal resistances can be calculated by means of the microclimate simulator.

In Connecticut maize, N.C. Turner and J.E. Begg measured stomatal resistance with an agitated diffusion porometer described by Slatyer (1966). The resistance approximately doubled between very bright sunlight and $0.3 \mathrm{ly} \mathrm{min}^{-1}$ insolation. In my calculations, this rule has been employed, equation (5). When minimum stomatal resistance 
for water vapor was set at $2 \mathrm{sec} \mathrm{cm}^{-1}$ expressed per surface area of epidermis, the synthetic air temperature at midcanopy was about $0.5 \mathrm{C}$ cooler than observed. On the other hand, when the minimum stomatal resistance was set at $6 \mathrm{sec} \mathrm{cm}^{-1}$, the synthetic air temperature was nearly a degree warmer than observed. Finally, when the minimum stomatal resistance was set at $3 \mathrm{sec} \mathrm{cm}^{-1}$, synthetic and observed temperatures were nearly identical, the synthetic was near the observed vapor pressure in the lower canopy (Fig. 15-2), and 90\% of the radiant energy absorbed by the canopy was expended in evaporation.

The microclimate simulator has led us to stomatal resistances for the canopy and has also calculated the corresponding leaf temperatures. When Lemon was observing the microclimate, the air temperature at canopy top was $22.3 \mathrm{C}$ and the temperature of the leaves according to the simulator varied from 22.3 at canopy top to 23.1 in the lowest stratum. If the $\mathrm{CO}_{2}$ concentration above and below the canopy and the physiology of corn leaves are specified, the photosynthesis simulator should now produce $\mathrm{CO}_{2}$ profiles similar to Lemon's observations and photosynthesis rates similar to his calculations.

Since maize was used to obtain the characteristics of a photosynthetic apparatus devoid of resistances, its interior physical resistances are set at zero. Further, maize seems the classic case of no light respiration. The dark respiration is set at $2 \mathrm{~F}$ and its $Q_{10}$ at 2 . The inner photosynthetic mechanism of maize is specified by a maximum of $180 \mathrm{~F}$ and Michaelis parameters of $300 \mathrm{ppm}$ and $0.5 \mathrm{ly} \mathrm{min}^{-1}$ for $\mathrm{CO}_{2}$ and insolation. Its $Q_{10}$ is set at 2 , which will apply between 20 and $30 \mathrm{C}$.

The $\mathrm{CO}_{3}$ concentrations at canopy top and bottom were 284 and 281 ppm. The sources of $\mathrm{CO}_{2}$ outside the leaf were the respiration of the stalk and ear. First, the respiration of the stem is estimated from Begg and Jarvis's (1968) observation that a stem of Stylosanthes humilis respired $4 \mathrm{~F}$ where area is the projected lateral area of the stem. If maize stalks respire at the same rate, 5 stalks $\mathrm{m}^{-2}$ that are $225 \mathrm{~cm}$ tall and have average width of $2 \mathrm{~cm}$ would respire $1 \mathrm{~F}$ where area is now of the land. This was assigned to $25-\mathrm{cm}$ strata according to the width of Connecticut corn stalks in mid-September. An ear that contained $45 \%$ water had a net respiration of about $0.7 \mathrm{mg} \mathrm{CO} \mathrm{g}^{-1} \mathrm{hr}^{-1}$ (Hesketh and Musgrave, 1962); and in mid-September, Connecticut corn had $45 \mathrm{~g}$ of ear in the fifth stratum, $125 \mathrm{~g}$ in the sixth $25-\mathrm{cm}$ stratum from the top, and the ear was $45 \%$ water. The respiration of stalk plus ear in $25-\mathrm{cm}$ strata from top to bottom was thus set at: .06, .06, .08, .11, 1.72, 4.53, $.14, .14, .16 \mathrm{~F}$. (The Connecticut maize was measured by J.E. Begg.) The respiration within the leaf had already been embodied in the simulator of the individual leaf, and the preceding specifications of sources $\mathrm{X}$; complete the preparation for the photosynthesis simulator.

The insolation normal to the leaves and the leaf area in each stratum is shown in Fig. 15-2 as employed in the photosynthesis simulator. According to the simulator, the canopy of leaves fixed $72 \mathrm{~F}$. Of this total, $49 \mathrm{~F}$ was obtained from the air above, $16 \mathrm{~F}$ from the soil, and $7 \mathrm{~F}$ from the stalk and ear of the canopy. How well does all this agree with observation?

The observations that can be compared to the calculations are those of $\mathrm{CO}_{2}$ concentration, Fig. 15-2. The minimum concentration according 

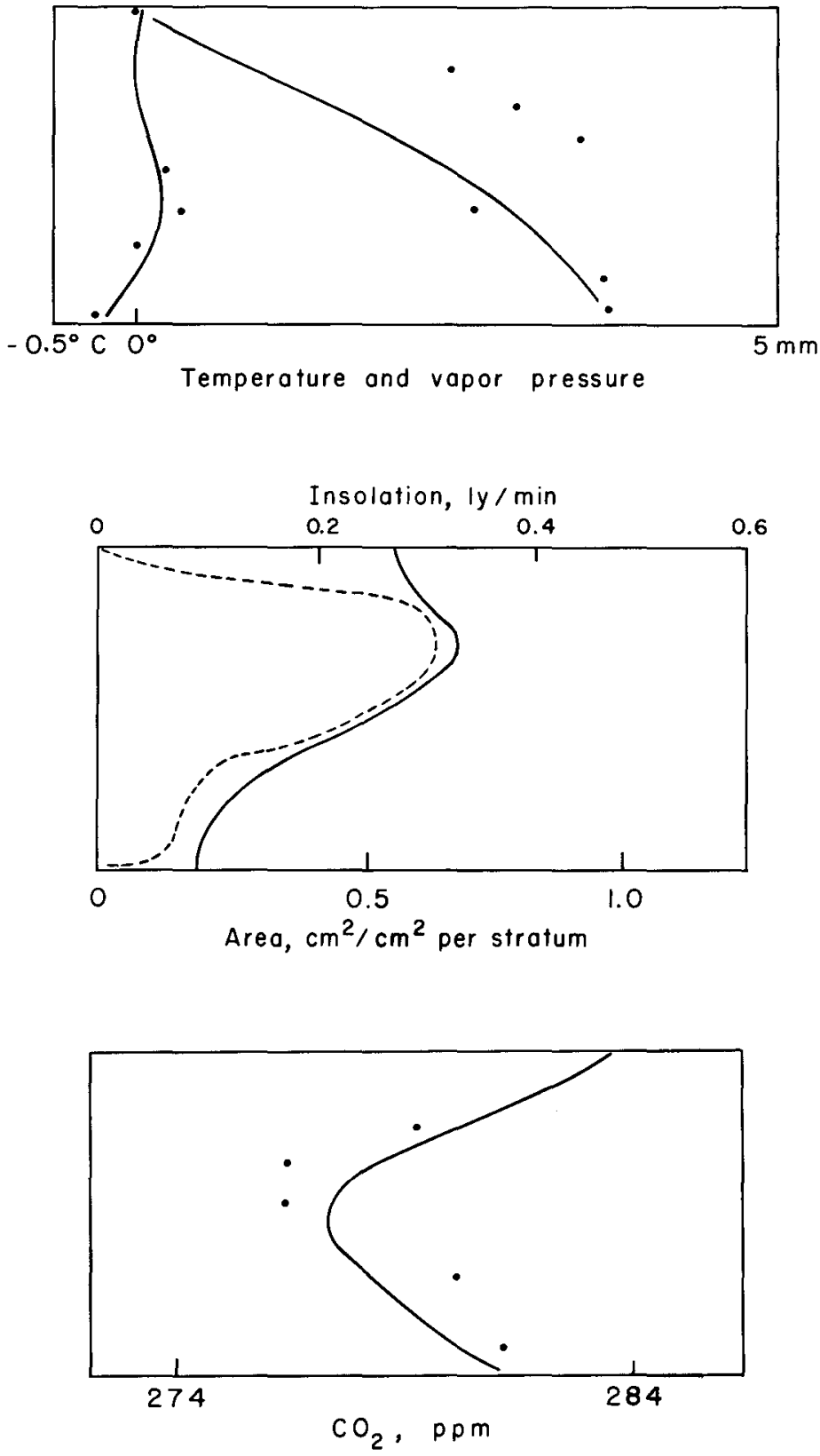

Fig. 15-2-Observations (Lemon, 1967) of temperature, water vapor pressure, and $\mathrm{CO}_{2}$ concentration in maize at midday are shown by dots. The simulations of these three factors are shown by curves. The measured leaf area is shown by a dashed curve, and the insolation per unit leaf area inferred by the areas and the observed extinction of insolation is shown by a solid curve. 
to the simulator ( $-8.5 \mathrm{ppm}$ less than at canopy top) agrees closely with the observed -8.0. Further, the heights of the simulated and observed minima are nearly the same. The disagreement between simulation and observation is about $150 \mathrm{~cm}$ from canopy top. There Lemon observed a sharp enrichment of $\mathrm{CO}_{2}$, and only a slight enrichment was simulated. In general the simulator behaved realistically, but can it be made to produce a $\mathrm{CO}_{2}$ enrichment just below midcanopy?

Since I decreased diffusivity rapidly in the upper but not the lower canopy-as the wind decreased, while Lemon calculated great diffusivities in the upper and slight ones in the lower canopy, the effect of his diffusivities upon the enrichment should be examined. Unfortunately, increasing upper and decreasing lower diffusivities causes an impoverishment, not the desired enrichment.

Another possibility is effectiveness of the lower leaves caused by old age. To test this possibility, the photosynthesis of the leaves in lower strata was decreased from $1 / 3$ in midcanopy to $2 / 3$ at the bottom. This raised the $\mathrm{CO}_{2}$ concentration in midcanopy by $2 \mathrm{ppm}$ but did not simulate the sharp curvature of the profile observed.

A final possibility that may occur to the reader is increasing the respiration of stalk and ear. This has not been pursued, however, because the rates employed were set by a priori evidence, and changing them would be the sort of a posteriorifiddling that makes simulation cunning instead of useful. Thus, the $\mathrm{CO}_{2}$ profile is left with the conclusion that a priori evidence on the metabolism of single leaves plus the logical frameworks of the microclimate and the photosynthesis simulators mimicks the temperature and $\mathrm{CO}_{2}$ profiles within the canopies in general, failing only to explain the remarkable enrichment observed just below midcanopy.

In addition to comparing simulation and observation, the simulated photosynthesis can be compared to rates calculated by the observer. Lemon calculated the net uptake of $\mathrm{CO}_{3}$ by the canopy, stalk and ear at 1358 hours to be $65 \mathrm{~F}$, entirely from the air. The simulator calculates precisely the same $65 \mathrm{~F}$, but it says that $16 \mathrm{~F}$ came from the soil. The disagreement between Lemon's calculation and mine concerning the $\mathrm{CO}_{2}$ from the soil seems caused by two things: First, my inability to find a physiological basis for a large evolution of $\mathrm{CO}_{2}$ from the lower canopy and a micrometeorological basis for insulating that evolved $\mathrm{CO}_{2}$ from the sink in the upper canopy; and second, his convention of showing no $\mathrm{CO}_{2}$ flux from the soil.

The differences between our calculations seem minor, however, when the difficulties of both calculations are reviewed. Lemon has had to skate on the thin ice of estimating diffusivities within a canopy. And I have undertaken to take data from single leaves in a laboratory to calculate how an entire canopy works when it is growing in Nature's soil, under her sun and in her wind. The clear identity of the parameters, the logical nature of the simulators, and the realism of their behavior all argue that they are useful means of predicting the outcome when we manipulate the environment of a crop. First, a standard case is established for comparison. 


\section{THE STANDARD CASE}

Canopy height, $100 \mathrm{~cm}$; stem height, $10 \mathrm{~cm}$; LAI, 4; foliage distributed as Normal Curve (Stephens, 1969).

At canopy top; air temperature, 20C; vapor pressure deficit, 10 $\mathrm{mm} \mathrm{Hg}$; full insolation, $1.2 \mathrm{ly} \mathrm{min}^{-1}$; net all-wave radiation, $0.68 \mathrm{ly}$ $\min ^{-1}$; wind, $225 \mathrm{~cm} \mathrm{sec}^{-1}$; diffusivity, $2,000 \mathrm{~cm}^{2} \mathrm{sec}^{-1}$.

Within the canopy; extinction coefficients for insolation, 0.5 , net radiation, 0.4 , and ventilation, 3. Minimum diffusivity, $200 \mathrm{~cm}^{2} \mathrm{sec}^{-1}$. Hg.

Near the soil; air temperature, 20C; vapor pressure deficit, $7 \mathrm{~mm}$

Physiological factors; stomatal minimum resistance $R_{\mathrm{Sm}}, 2$ sec $\mathrm{cm}^{-1}$, and $\mathrm{K}_{\mathrm{Sl}}, 0.28 \mathrm{ly} \mathrm{min}^{-1} ; \mathrm{P}_{\mathrm{X}}, 180 \mathrm{~F} ; \mathrm{K}_{\mathrm{cc}}, 300 \mathrm{ppm} ; \mathrm{K}_{\mathrm{cl}}, 0.5 \mathrm{ly}$ $\min ^{-1} ; Q_{p}, 2 ; W_{d x}, 2 F ; Q_{w d}, 2$; Efficient species: $W_{l x}, R_{\mathbf{i}}$ and Ro are 0 . Inefficient species: $\mathrm{W}_{\mathrm{lx}}, 10 \mathrm{~F} ; \mathrm{Q}_{\mathrm{wl}}, 2 ; \mathrm{R}_{\mathrm{i}}$ and $\mathrm{R}_{\mathrm{O}}$ are $1 \mathrm{sec} \mathrm{cm}^{-1}$.

Results: canopies consume $95 \%$ of absorbed radiation in transpira-
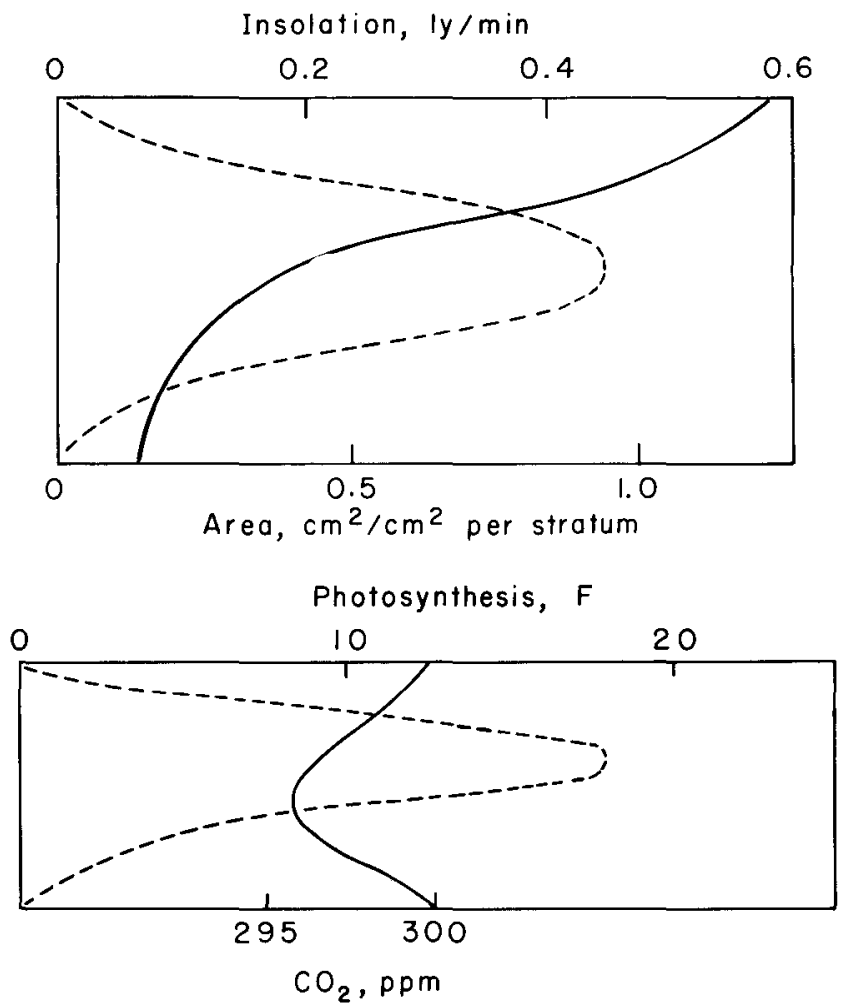

Fig. 15-3-Profiles of leaf area (dashed, top), insolation per leaf area (solid, top), $\mathrm{CO}_{\mathrm{a}}$ in the air (solid, bottom), and photosynthesis per land area (dashed, bottom) in the standard case. 
tion, and leaves are within $0.5 \mathrm{C}$ of air temperature. Efficient species fixes $76 \mathrm{~F}$, obtaining $21 \%$ from the soil while depleting the air by 4.3 ppm $\mathrm{CO}_{2}$. Inefficient species fixes $58 \mathrm{~F}$, obtaining $22 \%$ from the soil while depleting the air by $3.4 \mathrm{ppm} \mathrm{CO}_{2}$.

Subdividing the canopy into 8 or 18 strata for purposes of calculation causes no more than $3 \%$ difference.

Results are portrayed in Fig. 15-3.

Now that the simulators of microclimate and photosynthesis in a canopy have been established and the standard case defined, environmental manipulations can be made and compared in their effects upon photosynthesis.

\section{MANAGING STOMATA}

Stomatal management is a means of affecting photosynthesis and water use, too. True, stomata are on the plant's side of the boundary between environment and plant. But the simulators are especially suited to analyze the feedback that follows a stomatal change, and I arrogate "stomatal management" for this chapter.

At the beginning of this decade, confusion over diffusion theory caused many of us to believe stomata did not affect transpiration as long as they were open the weest crack. The discovery of chemicals that would shrink stomatal width without destroying the plant (Mateus Ventura, 1954; Zelitch, 1961) was soon followed by experiments that showed stomatal widths mattered throughout their range (Zelitch and Waggoner, 1962; Shimshi, 1963b; Slatyer and Bierhuizen, 1964). This salutary experience opened our eyes to sound theory that we had been overlooking (e.g., Penman and Schofield, 1951).

Outdoors, the transpiration of single plants (Shimshi, 1963a) of a barley (Hordeum vulgare) crop (Waggoner, Monteith, and Szeicz, 1964) and even of a large forest (Waggoner and Bravdo, 1967; Turner and Waggoner, 1968) have all been decreased significantly by stomatal management.

In a symposium concerning yields, however, one must remember that the $\mathrm{CO}_{2}$ for growth must also pass the stomatal resistance. Usually, the yield will be decreased, while water is saved by stomatal closure. There are two possible escapes from this predicament.

The first escape is to assume that the plant is suffering from dehydration that could be relieved by insulating it from the arid air with a net result of increased photosynthesis. This fortunate result seems most likely in the case of a brief period of drought susceptibility, as when maize is flowering. Ing. A. Munoz O. of Chapingo, Mexico (personal communication) and Waggoner (1966) have tried unsuccessfully to increase maize yields in this fashion.

Unfortunately, the chemical that they employed, phenylmercuric acetate (PMA), is toxic to the leaves. Thus it is unclear whether the the failure to increase yields by stomatal management was caused by the stomatal resistance to $\mathrm{CO}_{z}$ or by the toxicity of PMA.

The other escape from the predicament is to consider yields per gallon of water transpired. Because more things resist the gain of $\mathrm{CO}_{2}$ 
than oppose the loss of water by plants, photosynthesis should theoretically be decreased relatively less than transpiration by stomatal narrowing (Zelitch and Waggoner, 1962). This prediction has been verified in the laboratory and in controlled environments (Zelitch and Waggoner, 1962; Shimshi, 1963b; Slatyer and Bierhuizen, 1964; Davenport, 1966).

Outdoors, stomatal shrinking has decreased the growth of trees relatively more than it has decreased their evaporation (Turner and Waggoner, 1968). Here again, however, the toxic PMA was used, and we are uncertain whether growth was decreased mainly by the stomatal closure or by the toxicity of PMA. Fortunately the simulators are a guide to what would follow stomatal management that left all else unchanged.

The calculations are arranged in Table 15-1 to show how the shrinking of stomata would affect the net photosynthesis in sunny and cloudy times. The table also shows how stomatal change would affect the "transpiration ratio."

The transpiration ratio is not the yield per gallon; in fact, it is the reciprocal of a yield, an index of the inefficiency of the use of water. Long experience (e.g., Briggs and Shantz, 1913) has shown that evaporation usually consumes 200 to 2,000 units of water for each unit of growth. The consumption usually includes evaporation from the soil as well as transpiration from leaves. When evaporation from the soil is excluded and only daytime is considered, as in my calculations, the ratio should be lower. A canopy that consumes all net radiation received (about $60 \%$ of the insolation) and utilizes $10 \%$ of the visible radiation in photosynthesis theoretically has a transpiration ratio of only 90 (Slatyer, 1964).

Table 15-1 shows how both a rich and a poor plant would fare, and this makes a good place to begin discussing the table. Many studies (e.g., Black, 1966) have shown that rich, well watered, abundantly fertilized plants yield more per gallon. In other words, they have lower transpiration ratios. Does this prove that stomatal management that will usually decrease yield per acre is bound to increase the transpiration ratio disadvantageously? By separating two phenomena, the simulators show that disadvantage need not follow stomatal narrowing.

"Rich" means that the plant has the standard characteristics for simulating maize; i.e., $\mathrm{P}_{\mathrm{X}}$, the maximum photosynthesis attainable at $20 \mathrm{C}$, is $180 \mathrm{~F}$. "Poor," on the other hand, means that the crop is iden-

Table 15-1-Calculated effect of stomata upon photosynthesis in full sun and upon transpiration ratio in poor plants (maximum photosynthesis capacity $90 \mathrm{~F}$ ) and rich plants $(180 \mathrm{~F})$. The stomata have a constant resistance regardless of radiation, where noted, and otherwise vary with radiation as maize stomata do.

\begin{tabular}{lcccr}
\hline & \multicolumn{2}{c}{$\begin{array}{c}\text { Photosynthesis } \\
\text { Stomatal }\end{array}$} & F & \multicolumn{2}{c}{$\begin{array}{c}\text { Transpiration } \\
\text { ratio }\end{array}$} \\
\cline { 2 - 5 } $\begin{array}{c}\text { resistance } \\
\text { sec cm } \mathrm{cm}^{-1}\end{array}$ & $\begin{array}{c}\text { Poor } \\
\text { plants }\end{array}$ & $\begin{array}{c}\text { Rich } \\
\text { plants }\end{array}$ & Poor & $\begin{array}{c}\text { Rich } \\
\text { plants }\end{array}$ \\
\hline 2 (constant) & 41 & 82 & 300 & 150 \\
2 & 42 & 76 & 190 & 100 \\
8 & 28 & 37 & 90 & 70 \\
\hline
\end{tabular}


tical except $\mathrm{P}_{\mathbf{X}}$ is $90 \mathrm{~F}$. The simulators mimic the many experiments mentioned above: doubling the facility of the leaf doubles yield per acre and halves the transpirtation ratio in the first line of the table.

Now let us change evaporation and yield by changing stomata. In the first line of Table 15-1 we see that a canopy of poor leaves would fix $41 \mathrm{~F}$ if the stomata had a resistance of only $2 \mathrm{sec} \mathrm{cm}^{-1}$ throughout the canopy. But this isn't how stomata really behave: they shrink as illumination grows dimmer. Therefore, equation (5) was employed to narrow stomata normally in the sha de of the canopy, second line Table 1. The effect is surprising: although the stomatal resistance was changed from an unvarying 2 to a range from 2.4 at canopy to 13.0 at canopy bottom, the photosynthesis of a poor or rich plant was scarcely changed.

The paradox of increasing stomatal resistance scarcely changing the uptake of $\mathrm{CO}_{2}$ is caused by two processes. First, the large increase in stomatal resistance occurred in the lower half of the canopy, which was only fixing a third of the $\mathrm{CO}_{2}$. Second and surprising, stomatal shrinking in the shade kept the leaves from cooling $2 \mathrm{C}$ below and actually permitted them to warm $0.4 \mathrm{C}$ above air temperature at canopy top. Since gross photosynthesis far exceeded respiration and had a $Q_{10}$ of 2 , the obstruction of the stomata was compensated for by the warming of the leaves. The effect upon the transpiration ratio is, of course, spectacular because lower leaves with open stomata do transpire, fueling their evaporation with sensible heat from the air. Thus when stomata narrow naturally in the shade, the transpiration ratio in both crops decreases about a third.

If the insolation is $0.6 \mathrm{ly} \mathrm{min}^{-1}$, i.e., half full sunlight, the effect of stomatal variation upon the transpiration ratio is even greater.

These calculations were undertaken to demonstrate whether stomatal management could improve the transpiration ratio, and I seem to have gone astray, talking about the natural (not managed) variation of stomata. If this is a diversion, however, it is a strategic one to bring Nature to my side as a witness who has successfully evolved plants that shrink their stomata in the shade and save water.

Imagine that a chemical has been found that will change the minimum stomatal resistance $R_{S m}$ from 2 to 8 while leaving the natural response to shade. A comparison of lines 2 and 3 of Table 15-1 indicates that yields would be cut, but transpiration would be cut even more, and the transpiration ratio would decrease sharply. The outcome would be about the same in dimmer illumination or more humid air.

The transpiration ratios of 200 to 500 look very much like those observed in the USA Great Plains two generations ago by Briggs and Shantz. This testifies to the realism of the simulators. The transpiration ratio of 70, however, requires explanation since a lower limit of 90 was mentioned earlier. The limit of 90 was set by assuming that the net receipt of radiation was entirely consumed in evaporation. Where the ratio is less than 90 , on the other hand, stomatal closure has decreased evaporation to less than $60 \%$ of the net receipt of radiation. And this stomatal change has been attained in the theoretical canopy without changing any other characteristic of the plants.

Stomatal closure need not be by foreign chemical. It may be natural 
as in the pineapple (Ananas comosus), which transpires little (Ekern, 1965), grows well, and consequently has a transpiration ratio of only 50 (Joshi, Boyer, and Kramer, 1965).

Stomatal closure need not be by foreign chemical. It may be natural piration control. Epidermal coatings can also do the job, and they have been reviewed by Gale and Hagan (1966) and Waggoner (1967). If , however, the coating is practically impervious to both $\mathrm{CO}_{z}$ and water vapor and operates by obstructing diffusion, it merely changes $R_{S}$ as stomatal shrinkage does.

This concludes my examination of stomatal closure by the microclimate and photosynthesis simulators. Clearly, increasing yields per acre depends upon an improved hydration that we have not yet seen. On the other hand, if genetic or chemical stomata shrinkers that do nothing else can befound, they are not condemned by the example of rich-plantpoor-plant, and they should-like the natural closure of stomata in the shade-increase the yield per gallon.

\section{MANIPULATING LIGHT}

The management of light seems a likely means of increasing yields for we know that the photosynthesis of an entire canopy enclosed in a chamber is closely correlated with irradiance (Moss, Musgrave and Lemon, 1961), and the yield of a crop rises with increasing insolation (Stanhill, 1958). In dim light, the growth of even the shade-loving Impatiens increases as irradiance increases (Coombe, 1966), and in bright light the photosynthesis of even a single leaf of the efficient maize rises with rising radiation (Hesketh and Musgrave, 1962).

Two means of manipulating light come to mind. The antirainmaker could be asked to roll back the cloud. Or the light absorbed by the canopy could be increased by reflecting light that had escaped the foliage and reached the ground beneath the canopy.

Once again the simulators are the guide. The microclimate simulator should predict how the changes in radiation would alter leaf temperature and, then, the photosynthesis simulator how the changes in radiation and leaf temperature would alter the net uptake of $\mathrm{CO}_{2}$ into the entire canopy.

The first exercise,predicting the benefit of rolling away the clouds, is essentially calculating the response of the photosynthesis of an entire canopy to increased irradiance at canopy top. In this task I can employ the familiar "light response" curve and test the simulators further.

In Fig. 15-4 the upper curve represents the simulated net photosynthesis by the efficient species, which reaches $76 \mathrm{~F}$ in full sunlight. In the bright light the same canopy would fix only $58 \mathrm{~F}$ if the leaves belonged to the less efficient species.

Two things are immediately evident. First, the more efficient leaves make a canopy that responds more profitably to increasing light. But, second, then, the less efficient leaves fix considerably more $\mathrm{CO}_{3}$ in brighter light.

The virtue of more sunlight for an hour has, however, never been doubted by either botanists or bathers. A question more worthy of such 


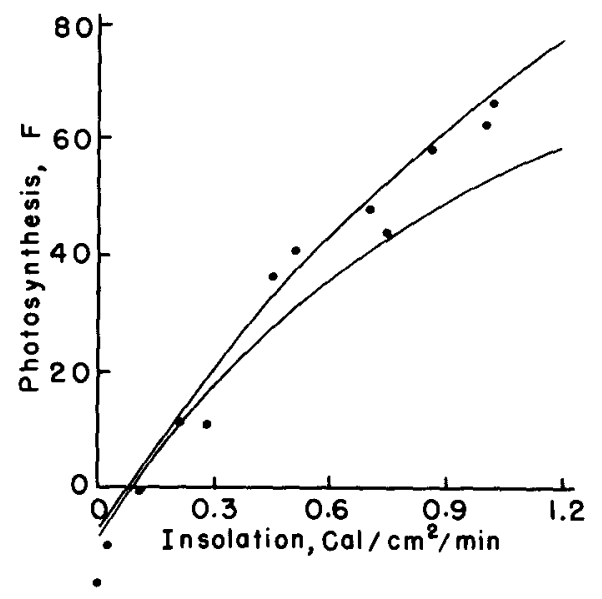

Fig. 15-4-Simulated photosynthesis in efficient and inefficient crops and the photosynthesis of maize canopy as observed by Moss et al. (1961). The simulations are shown by curves and the observations by dots.

a complicated simulator is, "In the long pull, how much yield would be added by more light ?" A single day can be examined.

The simulators in tandem have only been tested by comparing them with the single instance of Fig. 15-2 and must be tested by comparison against repeated observations during a full day before being employed to predict the outcome of a day. On September 3, 1958, Moss et al. (1961) measured the uptake of $\mathrm{CO}_{2}$ by a canopy of maize with an LAI of 4. If their observations taken periodically during the day are arranged according to the insolation received during these cloudless hours, the points of Fig. 15-4 are obtained. Since the observers included the respiration of the stem but the simulator did not, $7 \mathrm{~F}$ could be added to the observations; this would make the respiration in the dark nearly the same in both observation and simulation and would place the points for brighter light on or above the simulated curve. (The $7 \mathrm{~F}$ respired by stalks and ears of maize was calculated earlier for Fig. 15-2.) The agreement between observation and simulation is remarkable when we remember that the simulation was built up from elementary pieces of physiology and meteorology.

The next test is comparing the total simulated photosynthesis and respiration for 24 hours with actual measurements of growth. If the synthetic day were very bright, it might have $20 \%$ of its hours with full sunlight, $40 \%$ with half sunlight, and the remainder in darkness. Fully 690 ly of insolation would be received daily. If the net photosynthesis is added in the same fashion and converted into dry matter yield by multiplying by 0.65 , the daily accumulation is $46 \mathrm{~g} \mathrm{~m}^{-2}$. If the stem and ear respiration of $7 \mathrm{~F}$ is subtracted for every hour, the daily accumulation falls to $35 \mathrm{~g} \mathrm{~m}^{-2}$. Increasing the temperature to $30 \mathrm{C}$ would increase the yield from 35 to $42 \mathrm{~g} \mathrm{~m}^{-2}$.

The synthetic rates can be compared with short-term maximum 
rates: Pennisteum typhoides, $54 \mathrm{~g} \mathrm{~m}^{-2}$ (Begg, 1965); Sorghum vulgare and Zea mays, 51, Medicago sativa, 23 (Loomis and Williams, 1963). Thus the simple simulation of a day produces reasonable yields of dry matter, and calculating the effect of changed sunlight upon yields is worthwhile.

The first simulated change is halving the insolation. That is, $20 \%$ of the hours now receive half of full sunlight, $40 \%$ receive one-quarter of full sunlight, and the remainder are in darkness. Changing from the brighter day would decrease the accumulation of dry matter by the efficient canopy without stalks or ears from 46 to $19 \mathrm{~g} \mathrm{day}^{-1}$. The halving of sunlight more than halved daily accumulation because the daytime gains were nearly halved but the nighttime losses were unchanged.

During the 690-ly day, the less efficient species would produce 35 $\mathrm{g} \mathrm{m}^{-2}$. (Both the efficient canopy with stalks and ears and the inefficient canopy yield 35 .) In the inefficient canopy halving the insolation would decrease the accumulation to 18 or about half. The relative loss from halving insolation is somewhat less in the inefficient than in the efficient species because the relation between photosynthesis and insolation is more curved in the former than in the latter, Fig. 15-4.

The synthetic daily accumulation of $18 \mathrm{~g} \mathrm{~m}^{-1}$ by the inefficient species in a 350-ly day can be compared to peak growth rates of 32 to 21 in Beta maritima and Brassica oleracea in England where the daily insolation is 300 to 400 ly (Watson, 1958).

When one looks about for data to check the preceding prediction that halving radiation means halving yields, he is reminded of the difficulties of experimenting with environment. In a geographic survey (Begg, 1965) doubled insolation and doubled yields are found, but the difference in radiation is confounded with at least differences in temperature and species. On the other hand, when plants were grown beneath shades, halving insolation decreased maize grain and stover yield to about a third (Earley et al., 1966), and the growth of wheat (Triticum vulgare) was decreased $55 \%$ by $60 \%$ shade (Pendleton and Weibel, 1965), but the differences in radiation are confounded with at least differences in ven * tilation and humidity. Thus the data seem to need the simulators almost as much as the simulators need the data.

Taking survey, shades, and simulator together, one becomes confident that, within the range of natural insolation, increased insolation at canopy top would increase yield of many crops almost proportionally to the increase in light.

The foliage area affects the outcome of increased sunlight, and only an LAI of 4 has been discussed. The increase in hourly photosynthesis in the efficient canopy when the irradiance changes from half to full sunlight is $77 \%$ in Fig. 15-4 where LAI is 4 . If the LAI were only 2 , the increase would be only $68 \%$. If the LAI were 16 , net photosynthesis would more than double when insolation doubled as lower leaves left the parasitic, shaded category and made a contribution to net photosynthesis.

This role of LAI in light relations is clearly seen in the valuable diagram of Stern and Donald (1962) that shows growth of Trifolium subterraneum failing to respond to brighter light at LAI 2 and respond- 
ing sharply at LAI 8. LAI also has a great effect upon the outcome of tipping of leaves, which is a means of manipulating light that is discussed elsewhere in this book.

The simulators of this chapter will, of course, consider leaf angle. Leaf angle is indicated to the simulators by the extinction coefficient for net radiation of all wavelengths and the extinction coefficient for insolation.

The next subject, reflecting light into the canopy unlike managing leaf angle, is purely environmental management. Two sorts of reflectors have been employed. In one, the reflectors are placed to one side of the canopy and used to import sunlight (Pendleton et al., 1967). This resembles skip-row planting (Grissom and Spurgeon, 1963) with reflectors in the fallow rows. Since neither skip-row nor reflectors in fallow rows increases yield in proportion to the fallow area, however, I shall not consider it a means of increasing yield in a large area.

The second sort of reflector, on the other hand, does not import light from one side and seems an environmental manipulation for increasing yield. This reflector is put on the ground. It reflects back upon the canopy, especially the shaded lower leaves, light that otherwise would be wasted upon the ground or weeds.

In the standard case of full sunlight and an LAI of 4 with an extinction coefficient of 0.5 for light, $15 \%$ of the light reaches the soil. If this is reflected completely and absorbed with the same extinction coefficient as the insolation, $85 \%$ of the reflected radiation will be absorbed. Similarly the net radiation at the soil line is $21 \%$ of that above the canopy. This, too, must be reflected and considered by the simulators.

The reflection would warm the lowest leaves by $0.7 \mathrm{C}$, increase transpiration by $14 \%$, and increase photosynthesis $15 \%$ in the efficient or inefficient species. This is produced not only by warming of the lower leaves and decreasing the photochemical resistance, but also by opening the stomata in the lower leaves. In the lowest stratum, for example, the insolation per $\mathrm{cm}^{2}$ of leaf was increased from 0.08 to 0.17 ly $\mathrm{min}^{-1}$ with a consequent decrease in stomatal resistance from 12.7 to $6.4 \mathrm{sec} \mathrm{cm}^{-1}$. Now, how does this agree with observation?

In a cereal that transmitted 2 to $5 \%$ of the light through its canopy, a white plastic sheet upon the soil increased yield $5 \%$ more than did a black one. The corresponding increase in another cereal was 9\% (Pendleton, Brown, and Weibel, 1965).

In maize a similar reflector beneath the canopy of 40,000 plants/ha increased yield $13 \%$ and beneath 60,000 plants/ha increased yield $6 \%$ (Pendleton, Peters, and Peek, 1966). Thus experiments bear out the prediction of the simulators that the photosynthesis of a canopy will increase in about the same proportion as light absorption is increased by the reflection of sunlight that has reached the soil.

\section{MODIFYING THE WIND}

Managing the wind is a venerable way of modifying the environment of the crop. It is done by putting up a shelter belt of trees or pickets in places where the ventilation is overdone. Here, in Nebraska, the amelioration of crop environment by shelter has been studied for a long, long 
time. In reports that span 7 decades, Card (1897) told how a Nebraska windbreak made a crop noticeably taller, and Rosenberg (1966) related how a crop prospered within a shelter near Scottsbluff. Thorough reviews concerning windbreaks have been published (Chepil, 1965; van Eimern, 1968). In general, a shelterbelt decreases the wind downward to a distance about 20 times its height, decreases evaporation by a modest and variable amount, and improves plant growth somewhat outside the shade and inside the becalmed zone.

In recent years as we have come to think of photosynthesis as the diffusion of $\mathrm{CO}_{2}$ into a crop, however, we have sometimes taken a different tack. Since the turbulence of the air must deliver the $\mathrm{CO}_{2}$, a calm conceivably could limit that delivery and hence growth. No doubt the windbreaks produce their benefits by alleviating water stress and in spite of their hindering the delivery of $\mathrm{CO}_{2}$. As we push toward higher yields by removing such deficiencies as drought, will poor ventilation become significant?

The answer for a single, prosperous leaf in the calm of a bell jar seems clear. Its photosynthesis is hindered by calm air, and ventilation will increase its photosynthesis (Waggoner, Moss, and Hesketh, 1963).

In the case of single plants growing in a greenhouse or growth chamber, on the other hand, the results are usually described in a different light. That is, the experimenter concludes, not that wind is a good thing, but that moderate wind is tolerated by the plants (e.g., Whitehead, 1957).

The canopy of a crop presents a third situation where the air within the foliage may become nearly calm. The simulators consider that microclimate becalming, of course, and can predict whether decreasing ventilation, while leaving all else unchanged, would decrease yield significantly.

Ventilation of the standard canopy is determined by four factors. At canopy top, the wind is $225 \mathrm{~cm} \mathrm{sec}^{-1}$, and the diffusivity is $2,000 \mathrm{~cm}^{2}$ $\sec ^{-1}$. Within the canopy, the wind and diffusivity are both extinguished exponentially according to relative height and a coefficient of 3 . This rule is not permitted to decrease the diffusivity below a minimum of $200 \mathrm{~cm}^{2} \mathrm{sec}^{-1}$.

By varying these parameters, I shall examine how ventilation might change photosynthesis at full sunlight, when ventilation would most likely be limiting. At the same time, the relative contribution of $\mathrm{CO}_{2}$ from the soil to the canopy's photosynthesis can be seen. Further, the relation between the $\mathrm{CO}_{2}$ profile within the canopy and its uptake can be observed, Table 15-2.

The first, and most disappointing thing seen in Table 15-2 is the small range of the photosynthesis rates. The range in transpiration produced by this great range in ventilation is only $4 \%$, but the range in photosynthesis is even smaller: only $1.3 \%$. In these small differences the effect of temperature of the leaves upon photosynthesis as well as the delivery of $\mathrm{CO}_{2}$ comes into play.

The differences in ventilation have a more profound, if less practical, importance in governing where the carbon comes from. The range of soil contribution would be nearly 4-fold as ventilation changed.

The final entries in Table 15-2 are the maximum depletion of $\mathrm{CO}_{2}$ 
Table 15-2-The effects of changed ventilation upon the uptake of $\mathrm{CO}_{2}$ by a canopy, the percentage of $\mathrm{CO}_{z}$ that is obtained from the soil, and the maximum depletion of $\mathrm{CO}_{2}$ within the canopy air.

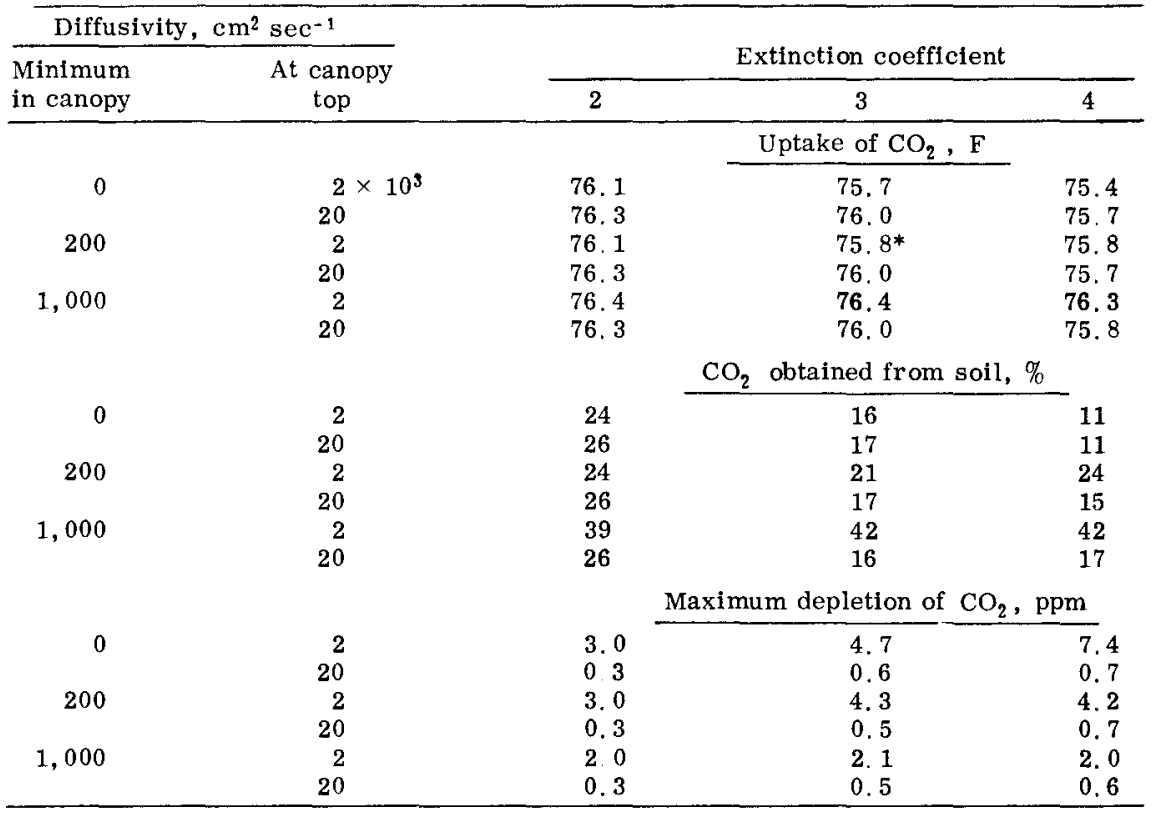

* Standard case.

within the bulk air of the canopy. It varies from only 0.3 to fully 7.4 $\mathrm{ppm}$. The first implication concerns the aerodynamic estimation of crop photosynthesis from the depletion or profile of $\mathrm{CO}_{2}$. Although the photosynthesis of this synthetic canopy varied less than $2 \%$, the $\mathrm{CO}_{2}$ depletion varied more than 10 -fold. Estimating the $2 \%$ change from a phenomena where 10-fold differences are occurring is fraught with difficulties, and the desperate need for an accurate means of measuring diffusivity was never clearer.

Despite the 10-fold difference in $\mathrm{CO}_{2}$ depletions, however, the actual magnitude of the depletions in the bulk air within the canopy is small relative to the $300 \mathrm{ppm}$ at canopy top and bottom. That is, less than a $3 \%$ decrease in $\mathrm{CO}_{2}$ has occurred in even the stillest air that I have specified. Therefore, one should not be surprised that the variations in photosynthesis caused by variations in ventilation are slight.

In the final calculations, the wind at canopy top was varied from 22 to the standard 225 and on to $1,225 \mathrm{~cm} \mathrm{sec}^{-1}$, a 56 -fold change in wind that produces a 7.5-fold change in boundary layer resistance. Once again, the change is disappointing: photosynthesis increases from 75.4 only to $76.2 \mathrm{~F}$ as the wind increases. The accompanying increase in canopy evaporation was somewhat more: $15 \%$.

In the paragraphs reporting the result of calculation, I have said that the benefits in increased photosynthesis from increased ventilation are disappointing. And surely they are for they never exceeded $2 \%$. But 
if we return to the subject of windbreaks, which opened this section of the paper, we shall find the results encouraging rather than disappointing.

In the opening paragraphs, the water conservation by a shelter was mentioned, and then concern lest this exact a toll in decreased delivery of $\mathrm{CO}_{2}$ was added. The calculations of the intervening paragraphs have calmed the concern: the decreased ventilation and water conservation will not exact a significant toll in growth. The slight decrease in $\mathrm{CO}_{2}$ availability should be easily counteracted by the improved hydration of the crop. These logical arguments lead, of course, to exactly the same conclusion reached by experimenters.

If windbreaks are that beneficial, why are they not universally used? Van Eimern (1968) suggests that a thorough analysis of the farming system would reveal that other costs such as establishment and maintenance and the occupation of valuable land would destroy the gains from increased yield. This is, of course, an economic result that the simulators cannot anticipate.

Finally, a similarity between the effects of stomatal and wind management should be discussed. Theoretically the narrowing of stomata would decrease transpiration more than photosynthesis because there are more obstacles to the uptake of $\mathrm{CO}_{2}$ than to the loss of water. This is shown in Table 15-1 where the transpiration ratio declines a third to a half when the minimum stomatal resistance is increased from 2 to 8 sec $\mathrm{cm}^{-1}$.

Since calmer air will also impede the exchange of both $\mathrm{CO}_{2}$ and water, it should decrease the amount of water required for the production of dry matter. This is borne out by the calculations for varied wind. Slowing the wind from 1,225 to $22 \mathrm{~cm} \mathrm{sec}^{-1}$, decreases the transpiration ratio from 108 to 96 . This change in the transpiration ratio summarizes both the advantage of wind management and the modest results that can be anticipated.

\section{FERTILIZING WITH CARBON DIOXIDE}

"Carbon dioxide has given the most spectacular yield increases of any growth factor yet discovered in the culture of greenhouse crops." Wittwer (1966) begins his comprehensive review of the enrichment of the plant environment with this enthusiastic sentence.

He also writes, "Comparable long time exposures to different atmospheric levels of carbon dioxide during a full production cycle of the major field crops. . . . have not been conducted, even experimentally. This is one of the most surprising deficiencies of modern research effort ...." The simulator reveals the reason for the deficiency.

Three sorts of calculations will be made. First, the $\mathrm{CO}_{2}$ concentration above and below the canopy will be increased as it is in greenhouses, and we shall see whether the field crop mimics that I have been using will behave as greenhouse crops do. Second, $\mathrm{CO}_{2}$ fertilization in the field will be attempted both by raising the $\mathrm{CO}_{2}$ concentration near the soil and by conducting $\mathrm{CO}_{2}$ into the canopy at various levels. Finally, the simulator should predict how the global increase in $\mathrm{CO}_{2}$ that $\mathrm{man}$ is causing will affect yields by the end of the century. 
The simulators have some convenient characteristics for these calculations. Obviously the $\mathrm{CO}_{z}$ injected into the air of the canopy is not all going to be added to the uptake of the foliage. Rather, some will go up, some down and some into the foliage. The balance among these currents depends upon concentrations or potentials and upon conductivities. These are precisely the factors that the simulators deal in. Also the increase in photosynthesis will not exactly follow the increase in concentration in the leaf interior for there will be a decreasing return. But this is all anticipated in the parameters $P_{X}$ and $K_{c c}$.

One feedback has not been built into the simulator, however: the effect of rising $\mathrm{CO}_{z}$ concentration in raising the stomatal resistance. This has been a particular concern of Heath and his colleagues. Heath and Russell (1954), for example, found that the viscous resistance of the leaf increased 10 -fold when $\mathrm{CO}_{2}$ increased from 290 to $840 \mathrm{ppm}$. If diffusive resistance is proportional to the cube root of viscous resistance (Waggoner, 1965), Heath and Russell's results indicate that doubling 300 ppm $\mathrm{CO}_{2}$ would double stomatal resistance.

In the examples that follow, the effect upon stomata of $\mathrm{CO}_{2}$ changes smaller than $50 \mathrm{ppm}$ has been ignored. When, however, a change from 300 to fully $600 \mathrm{ppm}$ is considered, the stomatal resistance will be doubled.

The first example, changing the concentration both above and below the canopy from 300 to $600 \mathrm{ppm}$, is the sort practiced by horticulturalists. The simulator indicates that the efficient crop without light respiration would increase its photosynthesis in bright light by $40 \%$ if the $\mathrm{CO}_{2}$ concentration were increased to $600 \mathrm{ppm}$, Table 15-3. At half of full sunlight the increase would be $37 \%$. At $690 \mathrm{ly} \mathrm{day}^{-1}$, the dry matter production would be increased $40 \%$ to fully $64 \mathrm{~g} \mathrm{~m}^{-2}$ day $^{-1}$.

Table 15-3-The effects of changed $\mathrm{CO}_{3}$ concentrations above and below a canopy of efficient leaves upon its uptake of $\mathrm{CO}_{2}$, the percentage of the $\mathrm{CO}_{2}$ that is obtained from the soil, and the maximum depletion of $\mathrm{CO}_{2}$ within the canopy air. Full sunlight.

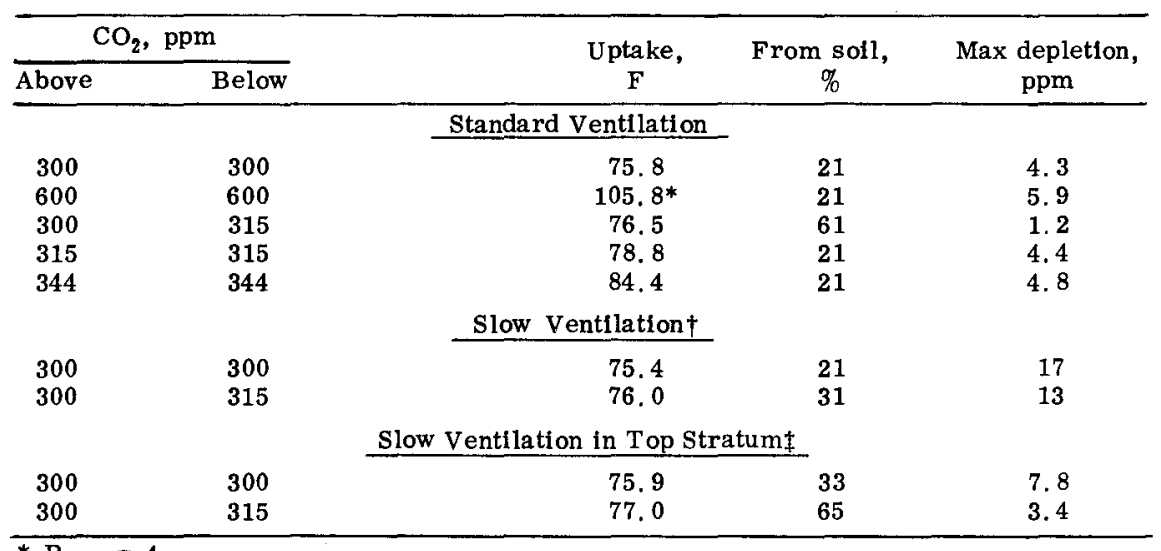

$* \mathrm{R}_{\mathrm{sm}}=4$

$\dagger$ At canopy top, diffusivity $=500 \mathrm{~cm}^{2} \mathrm{sec}^{-1}$ and wind $=100 \mathrm{~cm} \mathrm{sec}-1$.

¥ Standard diffusivity except $200 \mathrm{~cm}^{2} \mathrm{sec}^{-1}$ in top of eight strata. 


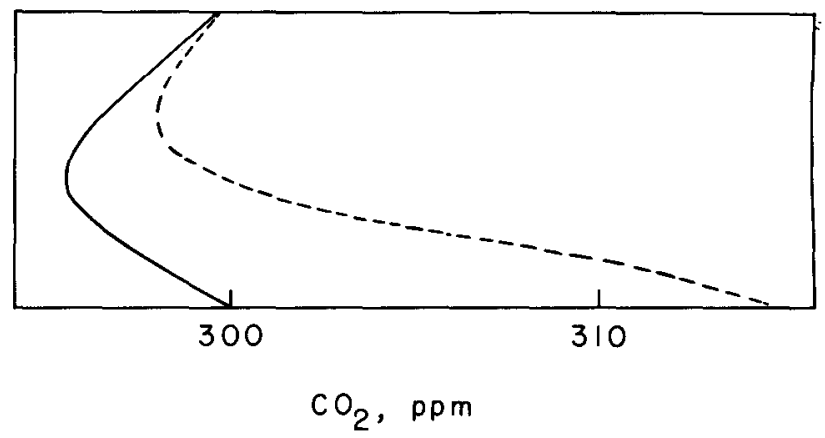

Fig. 15-5-Profiles of $\mathrm{CO}_{2}$ concentration in an inefficient canopy where the concentration near the ground is 300 or $315 \mathrm{ppm}$.

The less efficient species resembles more nearly the plants that have been grown in $\mathrm{CO}_{2}$-enriched air. At $690 \mathrm{ly} \mathrm{day}^{-1}$, the increase in yield would be $57 \%$. At $350 \mathrm{ly}$ day $^{-1}$, which resembles the greenhouse climate, the simulator indicates that doubling $\mathrm{CO}_{2}$ concentration above and below the canopy would increase by two-thirds the daily production of dry matter in this synthetic species. In fact, increases up to $88 \%$ were achieved in lettuce (Lactuca sativa) where the $\mathrm{CO}_{2}$ concentration was quadrupled (Wittwer, 1966).

The significant result of this exercise with the simulator is that field crops, even efficient ones such as maize, should respond greatly to $\mathrm{CO}_{2}$ fertilization. Recently Egli, Pendleton, and Peters (1968) reported that the daily photosynthesis of soybeans (Glycine max) was increased fully $72 \%$ when they were enclosed in a chamber and the $\mathrm{CO}_{3}$ concentration was maintained at $600 \mathrm{ppm}$ rather than the usual $300 \mathrm{ppm}$. Thus the potential for increased yields in field crops is available for $\mathrm{CO}_{2}$ enrichment and was rationalized by the simulator. The only question is how to deliver the $\mathrm{CO}_{2}$. Increasing the concentration near the ground as by heavy application of manure is tried first.

The consequence of increasing the $\mathrm{CO}_{2}$ near the soil from 300 to $315 \mathrm{ppm}$ is seen in the $\mathrm{CO}_{2}$ profiles of Fig. 15-5. The minimum concentration in mid-canopy is raised from 295.7 to 298.8. The concentration in the lower canopy is increased more, but these lower leaves are in limited light and can scarcely increase their photosynthesis. The consequence is a disappointing $1 \%$ increase in net photosynthesis.

The dramatic change is in the source of the $\mathrm{CO}_{2}$ taken into the leaves. Formerly $21 \%$ of the $76 \mathrm{~F}$ was taken from the soil line where the $\mathrm{CO}_{2}$ concentration near the soil conserves atmospheric $\mathrm{CO}_{2}$ ! What would happen if the canopy were less porous?

The porosity of the standard canopy is, of course, determined by the ventilation parameters: at canopy top a diffusivity of $2000 \mathrm{~cm}^{3}$ $\mathrm{sec}^{-1}$ and wind of $225 \mathrm{~cm} \mathrm{sec}{ }^{-1}$ and in the canopy an extinction coefficient of 3 and a minimum diffusivity of $200 \mathrm{~cm}^{2} \mathrm{sec}^{-1}$. This is not severe ventilation. Nevertheless, they can be decreased to the very quiet conditions of $500 \mathrm{~cm}^{2} \mathrm{sec}^{-1}$ and $100 \mathrm{~cm} \mathrm{sec} \mathrm{se}^{-1}$ at canopy top and a minimum of $50 \mathrm{~cm}^{2} \mathrm{sec}^{-1}$ within the canopy. The extinction coefficient is left at 3 . 
The transpiration from the canopy in full sunlight is decreased by $8 \%$ and the leaves in midcanopy are warmed $0.8 \mathrm{C}$ by the decrease in ventilation.

The effect upon $\mathrm{CO}_{z}$ exchange is tabulated in the lower lines of Table 15-3. The $\mathrm{CO}_{2}$ is depleted to $283 \mathrm{ppm}$ or $13 \mathrm{ppm}$ more than in the standard ventilation. The greater depletion of the $\mathrm{CO}_{2}$ decreases the photosynthesis from 75.8 to 75.4 .

The effect of the enrichment of the $\mathrm{CO}_{2}$ near the soil beneath a poorly ventilated canopy can now be seen. It is no greater than in a better ventilated canopy because the decreased diffusivity has insulated the active and numerous middle leaves from both the soil and the air at canopy top. The air in the top stratum can be made an insulator by decreasing its diffusivity to $200 \mathrm{~cm}^{2} \mathrm{sec}^{-1}$. while leaving the rest of the ventilation as in the standard case. This would warm the leaves somewhat and increase photosynthesis from 75.8 to $75.9 \mathrm{~F}$. Then raising the $\mathrm{CO}_{2}$ concentration near the soil from 300 to $315 \mathrm{ppm}$ would increase the photosynthesis from 75.9 to 77.0. That is, even this improbable ventilation does not permit a significant increase in $\mathrm{CO}_{2}$ uptake from an enrichment near the soil. We are left, therefore, with the inescapable conclusion that increasing the $\mathrm{CO}_{2}$ concentration near the soil will have little effect upon the photosynthesis in a canopy outdoors.

Another means of fertilizing with $\mathrm{CO}_{2}$ is piping gas into the field or scattering dry ice about. The experience of David Jordan of Tipton, Indiana is described in the July-August 1968 issue of The Furrow published by John Deere Co. In August he dropped 1-pound chunks of dry ice 25 feet apart in every direction in his maize field. The yield around the places where he dropped the dry ice was a third greater than in the rest of the field. The simulators can help us decide whether, in $\mathrm{Mr}$. Jordan's words, the increased yield was "a stroke of luck."

The application was $78 \mathrm{mg} \mathrm{CO}$ per $\mathrm{dm}^{2}$ or $78 \mathrm{~kg} \mathrm{ha}^{-1}$. I have calculated the effect upon the photosynthesis that would accompany additions of $5 \mathrm{~F}$ at full sunlight. If the dry ice applied by Jordan evaporated in 16 hours, the rate would have been $5 \mathrm{~F}$. Allowing the sun to shine at its full brightness for the full time should give the maximum response to the fertilization.

The calculation was accomplished by making the external source $\mathrm{X}$ of $\mathrm{CO}_{2}$ at the junction of stem and canopy equal to $5 \mathrm{~F}$. The result, Table 15-4, is a 0.1 enrichment of the air at midcanopy and a $0.02 \mathrm{~F}$ increase in photosynthesis. The increase represents a $0.4 \%$ recovery of the $5 \mathrm{~F}$ dry ice.

If the $\mathrm{CO}_{2}$ were added to the bottom of the poorly ventilated canopy, the increase would be somewhat more, $0.06 \mathrm{~F}$, but still too small to be significant, Table 15-4.

An alternative is adding the $\mathrm{CO}_{2}$ at midcanopy, i.e., about $60 \mathrm{~cm}$ from the canopy top. This is the bottom edge of the $38 \mathrm{~cm}$ of canopy that fixes $70 \%$ of the $\mathrm{CO}_{2}$ and is where $\mathrm{CO}_{2}$ depletion is greatest, Fig. 15-3. By adding the $5 \mathrm{~F}$ among these active leaves that have impoverished the air, one causes a somewhat greater increase in concentration and net photosynthesis. Nevertheless, the recovery of the $5 \mathrm{~F}$ of added $\mathrm{CO}_{2}$ would be only $4 \%$ in the poorly ventilated and $1 \%$ in the well-ventilated canopy. 
Table 15-4-The effects of external sources of $\mathrm{CO}_{2}$ within a canopy of efficient leaves upon its uptake of $\mathrm{CO}_{2}$, the percentage of $\mathrm{CO}_{2}$ that is obtained from the soil, and the maximum depletion of $\mathrm{CO}_{3}$ within the canopy air. Full sunlight.

\begin{tabular}{lccc}
\hline $\begin{array}{c}\text { External source, } \\
\text { F }\end{array}$ & $\begin{array}{c}\text { Uptake, } \\
\text { F }\end{array}$ & $\begin{array}{c}\text { From soll, } \\
\%\end{array}$ & $\begin{array}{c}\text { Max depletion, } \\
\text { ppm }\end{array}$ \\
\hline None & \multicolumn{2}{c}{ Standard Ventilation } & \\
5 at midcanopy & 75.83 & 21 & 4.3 \\
5 at canopy bottom & 75.89 & 19 & 3.8 \\
& 75.85 & 15 & 4.2 \\
None & \multicolumn{2}{c}{ Slow Ventilation } & \\
5 at midcanopy & 75.38 & 21 & 17 \\
5 at canopy bottom & 75.61 & 19 & 15 \\
\hline
\end{tabular}

Thus the simulators indicate that Jordan was most fortunate in getting such a large increase in maize yield or succeeded in concentrating the $\mathrm{CO}_{z}$ near the harvested plants.

In more general terms, crops would surely yield more if they grew in a richer $\mathrm{CO}_{2}$ environment, but our schemes seem sunk by the rock of delivery. This, not a lack of industry, is probably why agronomists have not shared the horticultural success with $\mathrm{CO}_{2}$ fertilization.

Although I have added $31 \mathrm{~F}$ ( 0.5 tons dry matter $\left.\mathrm{ha}^{-1} \mathrm{day}^{-1}\right)$ by raising the $\mathrm{CO}_{2}$ concentration near the soil or $5 \mathrm{~F}\left(120 \mathrm{~kg} \mathrm{CO}_{2} \mathrm{ha}^{-1}\right.$ ? day $^{-1}$ ) within the synthetic canopies, I have been unable to increase the photosynthesis in full sun substantially. The only way to manipulate the $\mathrm{CO}_{2}$ environment for higher yields seems to increase its concentration above as well as below the canopy. This is, of course, what is done in the greenhouse. It is also what we seem to be doing to the globe, and allows me to end by seeing a silver lining in the cloud of pollution.

During 1960-62 the $\mathrm{CO}_{z}$ concentration in the air over the northern Pacific Ocean was increasing $0.06 \mathrm{ppm}$ per month. At $41^{\circ} \mathrm{N}$ during December, 1961 the concentration was $315 \mathrm{ppm}$, not the $300 \mathrm{ppm}$ that we usually speak of (Bolin and Keeling, 1963). How has the increase to 315 ppm affected photosynthesis?

The increase in the $\mathrm{CO}_{2}$ concentration both above and below the canopy from 300 to $315 \mathrm{ppm}$ has, according to the simulators, increased photosynthesis by $4 \%$, Table 15-3.

If the increase continues, the concentration will reach $344 \mathrm{ppm}$ at the turn of the century. According to the simulator, this would raise photosynthesis about one-tenth above the rate of $300 \mathrm{ppm}$, Table 15-3, an increase that would be slightly moderated by narrower stomata. Thus, from what must be the only benefit ever attributed to pollution, we are receiving small and will receive somewhat larger yield increases from the $\mathrm{CO}_{2}$ generated by our furnaces and autos.

\section{SUMMARY}

The effect of environmental manipulation upon the photosynthesis and the yield of a crop canopy is explored by the use of mathematical 
models. These models or crop simulators use logical rules for calculation that not only estimate the amount of photosynthesis but also work in many ways like an actual crop.

The first or microclimate simulator accepts news of the weather above, the temperature and humidity of the air beneath the canopy, as well as the canopy architecture, stomatal resistance, absorption of radiation, and ventilation. From these factors the simulator calculates evaporation and the temperature of the air and the leaves within the canopy.

The second or photosynthesis simulator accepts the output of the first plus the following characteristics of the individual leaves:

1) Photochemical facility and how it varies with temperature, light and $\mathrm{CO}_{2}$ concentration

2) Dark respiration and how it varies with temperature

3) Light respiration and how it varies with temperature and light

4) The physical resistances to the current of $\mathrm{CO}_{2}$.

The second simulator also accepts the $\mathrm{CO}_{2}$ concentration above and below the canopy and currents of that gas that are injected or advected into the canopy at different levels. From this information, the simulator calculates the $\mathrm{CO}_{2}$ concentrations in the air and the photosynthesis in the leaves of the canopy.

Manipulating the leaf pores or stomata can decrease evaporation, and the simulators indicate that photosynthesis will be decreased relatively less. This is a different outcome than from a decrease in photochemical facility, which would decrease photosynthesis relatively more than evaporation.

Increasing the light either from above or below the canopy would increase assimilation nearly proportionally.

Since great differences in ventilation have little effect upon assimilation, the conservation of water by shelter extracts no hidden tax of decreased delivery of $\mathrm{CO}_{2}$ for photosynthesis.

Naturally ventilated canopies are very porous. Hence, the recovery by photosynthesis of $\mathrm{CO}_{2}$ released from dry ice or decay below or within the canopy is inefficient. On the other hand, the general increase of 0.72 ppm $\mathrm{CO}_{2}$ per year in the earth's atmosphere will increase photosynthesis in efficient species and full sunlight by $7 \%$ between now and the end of the century.

\section{LITERATURE CITED}

Altman, P. L., and D. S. Dittmer. 1966. Environmental biology. Fed. Am. Soc. Exp. Biol., Bethesda, Md. 694 p.

Begg, J. E. 1965. High photosynthetic efficiency in a low-latitude environment. Nature 205:1025-1026.

Black, C. A. 1966. Crop yields in relation to water supply and soil fertility, p. 177-206. In W. H. Pierre et al. (ed.) Plant environment and efficient water use. Amer. Soc. Agron., Madison, Wis. 295 p.

Bolin, B., and C. D. Keeling. 1963. Large-scale atmospheric mixing as deduced from the seasonal and meridional variations of carbon dioxide. J. Geophys. Res. 68:3899-3920. 
Bravdo, B. 1968. Decrease in net photosynthesis caused by respiration. Plant Physiol. 43:479-483.

Briggs, L. J., and H. L. Shantz. 1914. The relative water requirement of plants. J. Agr. Res, 3:1-65.

Card, F. W. 1897. Windbreaks. Nebraska Agr. Exp. Sta. Bull. 48:69-96.

Chepil, W. S. 1965. Transport of soil and snow by wind. Meteorol. Monogr. $6(28): 123-132$.

Davenport, D. C. 1966. Effects of phenylmercuric acetate on transpiration and growth of small plots of grass. Nature 212:801-802.

Decker, J. P. 1959. Comparative responses of carbon dioxide outburst and uptake in tobacco. Plant Physiol. 34:100-102.

Duncan, W. G., R. S. Loomis, W. A. Williams, and R. Hanau. 1967. A model for simulating photosynthesis in plant communities. Hilgardia 38:181-205.

Earley, E. B., R. J. Miller, G. L. Reichert, R. H. Hageman, and R. D. Seif, 1966. Effects of shade on maize production under field conditions. Crop Sci. 6:1-7.

Egli, D. B., J. W. Pendleton, and D. B. Peters. 1968. Photosynthetic rates of three natural soybean communities as related to carbon dioxide levels and solar radiation. Agron. Abstr. 1968:32.

Ekern, P. C. 1965. Evapotranspiration of pineapple in Hawaii. Plant Physiol. $40: 736-739$.

El-Sharkawy, M. A., R. S. Loomis, and W. A. Williams. 1967. Apparent reasimilation of respiratory carbon dioxide by different plant species. Physiol. Plantarum 20:171-186.

Gaastra, P. 1959. Photosynthesis of crop plants as influenced by light, carbon dioxide, temperature, and stomatal diffusion resistance. Mededel. Landbouwhogesch. Wageningen. 59:1-68.

Gale, J., and R. M. Hagan. 1966. Plant antitranpirants. Ann. Rev. Plant Physiol., p. 269-282.

Grissom, P. H., and W. I. Spurgeon. 1963. Skip-row plan increases yield on good land. Mississippi Farm Res. 26(1):1,8.

Heath, O.V.S., and J. Russell. 1954. Studies in stomatal behavior. VI. An investigation of the light responses of wheat stomata with the attempted elimination of control by the mesophyll. Part 2. Interactions with external $\mathrm{CO}_{2}$, and general discussion. J. Exp. Bot. $5: 269-292$.

Hesketh, J. D. 1963. Limitations to photosynthesis responsible for differences among species. Crop Sci. 3:493-496.

Hesketh, J. D., and D. N. Moss. 1963. Variation in the response of photosynthesis to light. Crop Sci. 3:107-110.

Hesketh, J., and R. B. Musgrave. 1962. Photosynthesis under field conditions. IV. Light studies with individual corn leaves. Crop Sci. $2: 311-315$.

Inoue, E. 1965 . On the $\mathrm{CO}_{2}$-concentration profiles within crop canopies. J. Agr. Meteorol. (Tokyo) 20:137-140.

Jackson, W. A., and R. J. Volk. 1968. Oxygen uptake by illuminated corn leaves. Agron. Abstr. 1968:35.

Joshi, M. C., J. S. Boyer, and P. J. Kramer. 1965. Growth, carbon dioxide exchange, transpiration, and transpiration ratio of pineapple. Bot. Gas. 126: 174-179.

Lake, J. V. 1967. Respiration of leaves during photosynthesis. I. Estimates from an electrical analogue. Aust. J. Biol. Sci. 20:487-493.

Lemon, E. R. 1967. Aerodynamic studies of $\mathrm{CO}_{2}$ exchange between the atmosphere and the plant, p. 263-290. In A. San Pietro, F. A. Greer, and T. J. Army (ed.). Harvesting the sun. Academic Press, New York.

Loomis, R. S., and W. A. Williams. 1963. Maximum crop productivity: an estimate. Crop Sci. 3:67-72.

Loomis, R. S., W. A. Williams, W. G. Duncan, A. Dovrat, and F. Nunez A. 1968. Quantitative descriptions of foliage display and light absorption in field communities of corn plants. Crop Sci. 8:352-356. 
Marsh, H. V., Jr., J. M. Galmiche, and M. Gibbs. 1965. Effect of light on the tricarboxylic acid cycle in Scenedesmus. Plant Physiol. 40:1013-1022.

Mateus Ventura, M. 1954. Action of enzymatic inhibitors on transpiration and the closing of stomata. II. Arsenite, 2, 4-dinitrophenol and janus green on isolated leaves of Stizolbium atterrimum. Rev. Brasil. Biol. 14:153-161.

Moss, D. N. 1965. Capture of radiant energy by plants. Meteorol. Monogr. $6(28): 90-108$.

Moss, D. N. 1966. Respiration of leaves in light and darkness. Crop Sci. 6: $351-354$.

Moss, D. N., R. B. Musgrave, and E. R. Lemon. 1961. Photosynthesis under field conditions. III. Some effects of light, carbon dioxide, temperature, and soil moisture on photosynthesis, respiration, and transpiration of corn. Crop Sci. 1:83-87.

Pendleton, J. W., C. M. Brown, and R. O. Weibel. 1965. Effect of reflected light on small grain yields. Crop Sci. 5:373.

Pendleton, J. W., D. B. Egli, and D. B. Peters. 1967. Response of Zea mays L. to a "light rich" field environment. Agron. J. 59:395-397.

Pendleton, J. W., D. B. Peters, and J. W. Peek. 1966. Role of reflected light in the corn ecosystem. Agron. J. 58:73-74.

Pendleton, J. W., and G. E. Smith. 1967. Corn plant of the future. Crops and Soils Mag. 19(8):9.

Pendleton, J. W., and R. O. Weibel. 1965. Shading studies on winter wheat. Agron. J. 57:292-293.

Penman, H. L., and R. K. Schofield. 1951. Some physical aspects of assimilation and transpiration. Symp. Soc. Exp. Biol. 5:115-129.

Rosenberg, N. J. 1966. Microclimate, air mixing and physiological regulation of transpiration as influenced by wind shelter in an irrigated bean field. Agr. meteorol. 3:197-224.

Shaw, R. H., and C. R. Weber. 1967. Effects of canopy arrangements on light interception and yield of soybeans. Agron. J. 59:155-159.

Shimshi, D. 1963. Effect of chemical closure of stomata on transpiration in varied soil and atmospheric environments. Plant Physiol. 38:709-712.

Shimshi, D. 1963. Effect of soil moisture and penylmercuric acetate upon stomatal aperture, transpiration and photosynthesis. Plant Physiol. 38:713-721.

Slatyer, R. O. 1964. Efficiency of water utilization by arid zone vegetation. Ann. Arid Zone. 3:1-12.

Slatyer, R. O. 1966. In situ measurements of stomatal resistance, p. 5-6. In Conference on instrumentation for plant environment measurements. CSIRO Div. Meteorol. Physl. Aspendale, Australia.

Slatyer, R. O., and J. F. Bierhuizen. 1964. The effect of several foliar sprays on transpiration and water use efficiency of cotton plants. Agr. Meteorol. $1: 42-53$.

Stanhill, G. 1958. Effects of soil moisture on the yield and quality of turnips. II. Response at different growth stages. J. Hort. Sci. 33:264-274.

Stephens, G. R. 1969. Dry matter productivity of red pine. I. Foliage distribution in tree crown and stand canopy. Agr. Meteorol. In press.

Stern, W. R., and C. M. Donald. 1962. Influence of leaf area and radiation on the growth of clover in swards. Aust. J. Agr. Res. 13:615-623.

Turner, N. C., and P. E. Waggoner. 1968. Effects of changing stomatal width in a red pine forest on soil water content, leaf water potential, bole diameter and growth. Plant Physiol. 43:973-978.

Uchijima, Z. 1962. Studies on the micro-climate within the plant communities. 1. On the turbulent transfer coefficient within plant layer. J. Agr. Meteorol. (Tokyo) 18:1-9.

Van Eimern, J. 1968. Problems of shelter planting, p. 157-166. In Agroclimatological methods. Proceedings of the Reading symposium. Unesco, Paris. $392 \mathrm{p}$. 
Waggoner, P. E. 1965. Calibration of a porometer in terms of diffusive resistance. Agr. Meteorol. 2:317-329.

Waggoner, P. E. 1966. Decreasing transpiration and the effect upon growth, p. 49-72. In W. H. Pierre et al. (ed.) Plant environment and efficient water use. Amer. Soc. Agron., Madison, Wis.

Waggoner, P. E. 1967. Moisture loss through the boundary layer, p. 41-52. In S. W. Tromp and W. H. Wiche (ed.). Biometeorology, Vol. 3. Proc. 4th Int. Biometeorol. Congr., New Brunswick. Swets and Zeitlinger Publ. Co., Amsterdam.

Waggoner, P. E. 1969. Predicting the effect upon net photosynthesis of changes in leaf metabolism and physics. Crop Sci. In press.

Waggoner, P. E., and B. Bravdo. 1967. Stomata and the hydrologic cycle. Proc. Nat. Acad. Sci. 57:1096-1102.

Waggoner, P. E., G. U. Furnwal, W. E. Reifsnyder. 1969. Simulation of the microclimate in a forest. Forest Sci. 15:37-45.

Waggoner, P. E., D. N. Moss, and J. D. Hesketh. 1963. Radiation in the plant environment and photosynthesis. Agron. J. 55:36-39.

Waggoner, P. E., J. L. Monteith, and G. Szeicz. 1964. Decreasing transpiration of field plants by chemical closure of stomata. Nature 201:97-98.

Waggoner, P. E., W. E. Reifsnyder. 1968. Simulation of the temperature, humidity and evaporation profiles in a leaf canopy. J. Appl. Metrol. 7(3):400-409.

Watson, D. J. 1958. The dependence of net assimilation rate on leaf-area index. Ann. Bot., N.S. 22:37-54.

Whitehead, F. H. 1957. Wind as a factor in plant growth, p. 84-95. In J. P. Hudson (ed.) Control of the plant environment. Academic Press, Inc., N.Y.

Zelitch, I. 1961. Biochemical control of stomatal opening in leaves. Proc. Nat. Acad. Sci. U.S. 47:1423-1433.

Zelitch, I. 1966. Increased rate of net photosynthetic carbon dioxide uptake caused by the inhibition of glycolate oxidase. Plant Physiol. 41:1623-1631.

Zelitch, I., and P. E. Waggoner. 1962. Effect of chemical control of stomata on transpiration and photosynthesis. Nat. Acad. Sci. Proc. 48:1101-1108 and 1297-1299. 